\title{
To settle or to move? The interplay between two classes of cyclic lipopeptides in the biocontrol strain Pseudomonas CMR12a
}

\author{
Jolien D'aes, ${ }^{1}$ Nam Phuong Kieu, ${ }^{1}$ Valérie Léclère, ${ }^{2}$ \\ Caroline Tokarski, ${ }^{3}$ Feyisara Eyiwumi Olorunleke, ${ }^{1}$ \\ Katrien De Maeyer, ${ }^{1}$ Philippe Jacques, ${ }^{2}$ \\ Monica Höfte ${ }^{1 *}$ and Marc Ongena ${ }^{4}$ \\ ${ }^{1}$ Laboratory of Phytopathology, Faculty of Bioscience \\ Engineering, Ghent University, Ghent, Belgium. \\ 2 ProBioGEM Laboratory UPRES-EA 1026 and \\ ${ }^{3}$ Miniaturisation pour la Synthèse, l'Analyse \& la \\ Protéomique (MSAP), USR CNRS 3290, and \\ Protéomique, Modifications Post-traductionnelles et \\ Glycobiologie, IFR 147, Université de Lille 1-Sciences et \\ Technologies, Villeneuve d'Ascq Cedex, France. \\ ${ }^{4}$ Gembloux Agro-Bio Tech, University of Liège, \\ Gembloux, Belgium.
}

\section{Summary}

Pseudomonas CMR12a is a biocontrol strain that produces phenazine antibiotics and as yet uncharacterized cyclic lipopeptides (CLPs). The CLPs of CMR12a were studied by chemical structure analysis and in silico analysis of the gene clusters encoding the non-ribosomal peptide synthetases responsible for CLP biosynthesis. CMR12a produces two different classes of CLPs: orfamides B, D and E, whereby the latter two represent new derivatives of the orfamide family, and sessilins A-C. The orfamides are made up of a 10 amino acid peptide coupled to a $\beta$ hydroxydodecanoyl or $\beta$-hydroxytetradecanoyl fatty acid moiety, and are related to orfamides produced by biocontrol strain Pseudomonas protegens Pf-5. The sessilins consist of an 18-amino acid peptide linked to a $\beta$-hydroxyoctanoyl fatty acid and differ in one amino acid from tolaasins, toxins produced by the mushroom pathogen Pseudomonas tolaasii. CLP biosynthesis mutants were constructed and tested for biofilm formation and swarming motility. Orfamides appeared indispensable for swarming while sessilin mutants showed reduced biofilm formation, but enhanced swarming motility. The

Received 20 October, 2013; revised 14 February, 2014; accepted 15 February, 2014. *For correspondence. E-mail monica.hofte@ ugent.be; Tel. (+32) 926460 17; Fax (+32) 92646238. interplay between the two classes of CLPs fine tunes these processes. The presence of sessilins in wild type CMR12a interferes with swarming by hampering the release of orfamides and by co-precipitating orfamides to form a white line in agar.

\section{Introduction}

Cyclic lipopeptides (CLPS) are bacterial metabolites composed of a cyclic oligopeptide coupled to a fatty acid tail. They are synthesized by non-ribosomal peptide synthetases (NRPS), encoded on large gene clusters (Finking and Marahiel, 2004). CLPs are known for their powerful activity against a wide range of organisms, such as fungi, bacteria, protozoa and plants (Raaijmakers et al., 2006; 2010; D'aes et al., 2010). This activity has been attributed mainly to pore formation and membrane destabilization as a consequence of their amphiphilic nature. Bacterial genera capable of CLP synthesis are quite diverse, including Burkholderia, Lyngbya, Streptomyces, Bacillus and Pseudomonas spp. Many studies about CLPs have focused on plant pathogenic Pseudomonas spp., where they often play a role in virulence (Scholz-Schroeder et al., 2001; Kunkel and Zhongying, 2006; Pauwelyn et al., 2013). However, several plant commensal or beneficial pseudomonads also produce CLPs, in which case they are involved in a wide range of natural functions, such as motility (Andersen et al., 2003), biofilm formation (Roongsawang et al., 2003; De Bruijn et al., 2008) and even defence against predation (Mazzola et al., 2009). One main draw of CLP-producing pseudomonads is their potential as biological control agents, although in only a few cases it was proved that the observed biocontrol activity was at least partly due to the action of CLPs (D'aes et al., 2010).

Pseudomonas CMR12a was isolated from the rhizosphere of tropical tuber crop cocoyam (Xanthosoma sagittifolium) in Cameroon. Taxonomically, Pseudomonas CMR12a belongs to the Pseudomonas fluorescens complex (Mavrodi et al., 2010), positioned between the Pseudomonas protegens and Pseudomonas chlororaphis group (B. Ruffner, M. Péchy-Tarr, M. Höfte, G. Bloemberg, J. Grunder, C. Keel and M. Maurhofer, in preparation). The strain has two quorum-sensing systems (De Maeyer 


\section{J. D'aes et al.}

et al., 2011) and produces several metabolites, including phenazines and two different classes of CLPs (De Maeyer et al., 2013). Phenazines are coloured aromatic compounds, which are well studied regarding their biosynthesis, regulation and antibiotic activity (Mavrodi et al., 2006). Perneel and colleagues (2007) showed that CMR12a produces two phenazines, namely phenazine-1carboxylate and phenazine-1-carboxamide. Concerning the nature of the CLPs produced by CMR12a however, only preliminary results were presented to date. D'aes and colleagues (2011) showed that the first CLP had a molecular weight of $2028 \mathrm{Da}$ and that for the second CLP type, three main compounds with molecular ions of 1253 , 1279 and $1281 \mathrm{Da}$ were detected. CMR12a is able to provide protection against several soil-borne diseases, including root rot on cocoyam and on bean caused by Pythium myriotylum (Perneel et al., 2007) and Rhizoctonia solani respectively. In addition, we demonstrated that phenazines and at least one of the CLPs are involved in the biocontrol activity of CMR12a against R. solani (D'aes et al., 2011).

In this work, we performed an in-depth characterization of the CLPs produced by CMR12a by combining two approaches, namely genetic analysis of the NRPS genes responsible for CLP biosynthesis and chemical structure analysis. Based on data from genome mining, new biosynthesis mutants were generated to test for a possible role of these CLPs in crucial functions for rhizosphere fitness, i.e. motility and biofilm development. These experiments revealed not only that the two CLPs appear to play important and differential roles in biofilm formation and swarming, but also that they may chemically interact to yield an insoluble form visualized as a white line surrounding colonies.

\section{Results}

\section{Structural characterization of the CLPs produced by} Pseudomonas sp. CMR12a

Preliminary analysis of a crude extract by highperformance liquid chromatography (HPLC)-coupled electrospray mass spectrometry (LC-ESI-MS) analysis revealed that CMR12a probably produces at least two different types of lipopeptides on King's medium B (KB) agar, as presented in Fig. 1. These two CLPs were designated CLP1 and CLP2 originally (D'aes et al., 2011) but were renamed sessilin and orfamide respectively. For the sessilin group, one main compound could be detected (marked as S-A in Fig. 1), which was purified and analysed in detail. The orfamide cluster showed three plain peaks (Ofa-B, Ofa-D and Ofa-E in Fig. 1), and all three compounds were selected for further analysis.

We purified the selected fractions by semi-preparative reverse phase HPLC, and fractions S-A and Ofa-E were

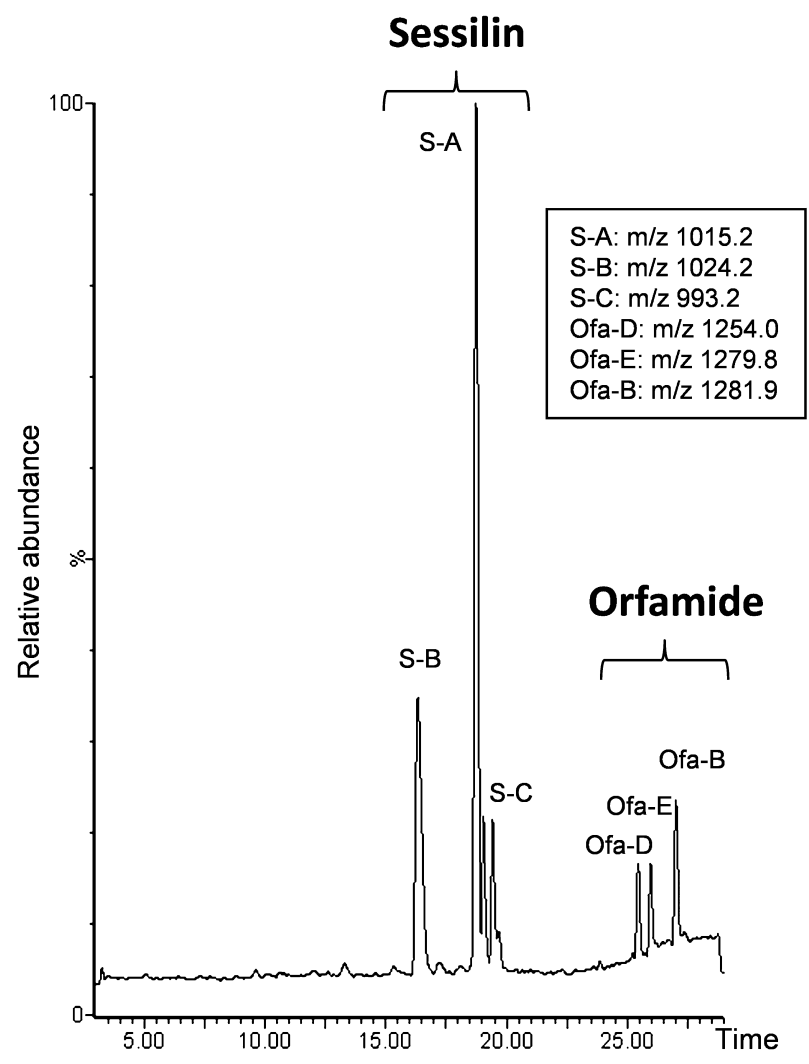

Fig. 1. Representative LC-ESI-MS profile of lipopeptides produced by Pseudomonas CMR12a grown on KB agar medium for 3 days. Detection was performed in the SCAN mode (total ion counts, $\mathrm{m} / \mathrm{z}$ range 900-2040). Molecular masses of the most abundant ion corresponding to each peak are indicated in the boxed insert.

submitted to quantitative amino acid analysis after total acid hydrolysis. Fraction S-A contained amino acids Glx, Ser, Hse, aThr, Val, lle, Leu, Lys and Pro in a molar ratio of $2: 1: 1: 1: 3-4: 1: 3: 1: 1$. Two additional minor peaks were observed in the hydrolysate, which could not be assigned to an available amino acid standard, and might be attributed to dhAbu and Dab (see below) (Supporting Information Fig. S1). Diode array UV trace in HPLC revealed that aromatic amino acids, which absorb at $254 \mathrm{~nm}$, are not present in the peptide backbone. Analysis of fraction Ofa-E revealed a molar ratio of 1-2:1-2:1:2:4 for Glx, Ser, aThr, Val and Leu respectively (Supporting Information Fig. S2).

Further structural identification of the lipopeptides was performed using high-resolution mass spectrometry. Nano electrospray ionization Qh Fourier transform ion cyclotron resonance mass spectrometry (NanoESI-QhFT-ICR MS) analysis of main sessilin fraction S-A showed the presence of one intense doubly charged ion with composition $\mathrm{C}_{96} \mathrm{H}_{168} \mathrm{O}_{25} \mathrm{~N}_{22}(\Delta \mathrm{m}=1.08$ p.p.m.) (Supporting Information Fig. S3A, theoretical spectrum shown in Supporting Information Fig. S3B). The uncharged 
molecular formula corresponding to the detected molecule was $\mathrm{C}_{96} \mathrm{H}_{166} \mathrm{O}_{25} \mathrm{~N}_{22}$. A minor doubly charged ion was also detected on Supporting Information Fig. S3A (theoretical spectrum shown in Supporting Information Fig. S3C), which could be correlated to molecular composition $\quad \mathrm{C}_{96} \mathrm{H}_{166} \mathrm{O}_{25} \mathrm{~N}_{22} \quad(\Delta \mathrm{m}=0.88$ p.p.m.; uncharged molecular formula: $\mathrm{C}_{96} \mathrm{H}_{164} \mathrm{O}_{25} \mathrm{~N}_{22}$ ), pointing to one unsaturation in the fatty acid moiety.

The exact structure of sessilin A (S-A) (Table 1) was identified using electron capture dissociation (ECD) experiments. S-A turned out to be related to tolaasin (Bassarello et al., 2004), a toxin-like CLP that is produced by Pseudomonas tolaasii Paine 1919 (type strain NCPPB 2192), the causal agent of brown blotch on cultivated mushrooms (Nutkins et al., 1991). The CLP is thus made up of a partially cyclized 18 -amino acid peptide chain coupled to a $\beta$-hydroxyoctanoyl fatty acid moiety. As shown by the generated $b^{+}\left(b_{1}{ }^{+}, b_{2}{ }^{+}, b_{4}{ }^{+}\right.$to $\left.b_{11}{ }^{+}\right)$and $z^{+}$ $\left(z_{5^{+*}}, z_{7^{+\bullet}}\right.$ to $\left.z_{13^{+\bullet}}, z_{15^{+*}}, z_{16^{+*}}\right)$ fragment ions from the linear part of the S-A chain (Supporting Information Fig. S4; Supporting Information Table S1), the difference between tolaasin and sessilin is due to the sixth amino acid residue of the peptide chain, which is a serine in tolaasin and a glutamine in S-A. From accurate $\mathrm{m} / \mathrm{z}$ ions of $\mathrm{S}-\mathrm{A}$ and its fragments (Supporting Information Table S1), and by analogy with the tolaasin structure (Bassarello et al., 2004), we could conclude that the cyclized part of the cycle contains Thr-lle-Hse-Dab-Lys amino acids linked via a lactone ring formed between the hydroxyl group of Thr and the C-terminal part of Lys.

In addition to the main form of tolaasin, tolaasin I, five other tolaasin derivatives exist that slightly differ with respect to the nature of the fatty acid chain, the nature of the amino acid residues at positions 15 and 16 of the peptide backbone, and the occurrence of an acyclic derivative (Nutkins et al., 1991; Bassarello et al., 2004). In the LC-ESI-MS analysis of CMR12a supernatant extract, we observed at least two additional minor peaks in the vicinity of the main sessilin compound, which were marked as sessilin B (S-B) and sessilin C (S-C) in Fig. 1. S-B presented a doubly charged $[\mathrm{M}+2 \mathrm{H}]^{2+}$ ion at $\mathrm{m} / \mathrm{z}$ 1024.2, corresponding to a mass gain of one water molecule compared with the main compound S-A. This suggested that it may represent an acyclic derivative of S-A, obtained from hydrolysis of its lactone ring, similar to tolaasin C. Such a linear structure is supported by the $y$ ion series yielded upon in source fragmentation (data not shown). Concerning S-C, a difference of 22 mass units of the $[\mathrm{M}+2 \mathrm{H}]^{2+}$ ion compared with that of S-A might correspond to a substitution of Hse16 by glycine, analogous to Tolaasin II (data not shown). However, the structures of S-B and S-C remain to be clearly established by more accurate analyses. Nevertheless, these three compounds appeared to be closely related, and their

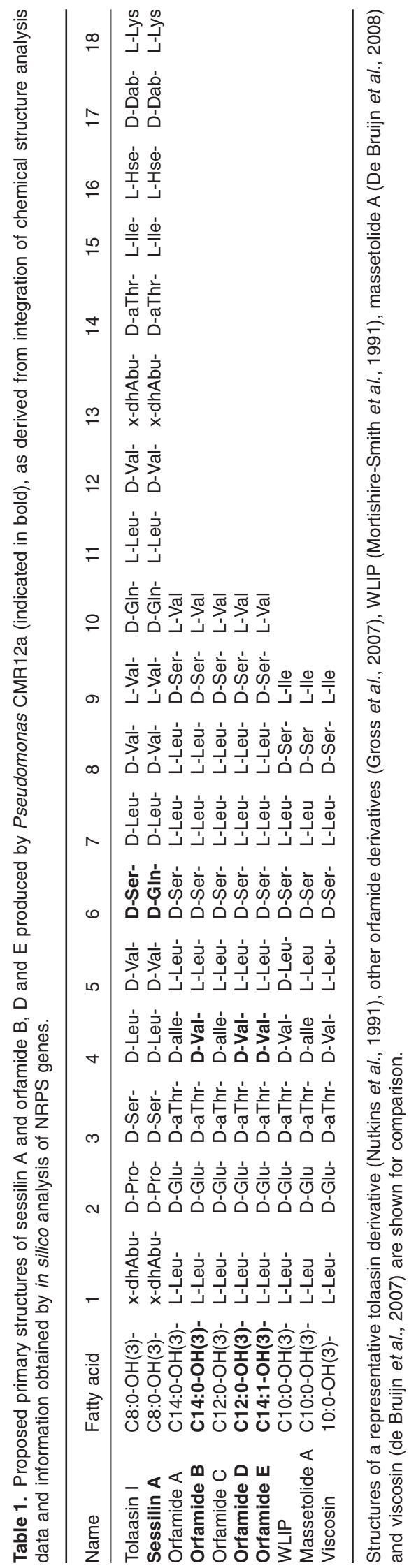


production was concomitantly abolished in the sessilin mutant of CMR12a (see below) (Supporting Information Fig. S7), indicating that they are synthesized via the same NRPS.

High-resolution MS analyses of the orfamide fractions (Ofa-B, Ofa-D, Ofa-E) resulted in detection of three main compounds, with molecular formulae $\mathrm{C}_{63} \mathrm{H}_{112} \mathrm{O}_{17} \mathrm{~N}_{10}$, $\mathrm{C}_{61} \mathrm{H}_{108} \mathrm{O}_{17} \mathrm{~N}_{10}$ and $\mathrm{C}_{63} \mathrm{H}_{110} \mathrm{O}_{17} \mathrm{~N}_{10}$ respectively (data not shown). ECD experiments for each compound (Supporting Information Fig. S5 for fraction Ofa-E) yielded identification of identical $\mathrm{y}^{+}$series ions $\left(\mathrm{y}_{8}{ }^{+}\right.$and $\left.\mathrm{y}_{9}{ }^{+}\right)$, proving that the peptide sequence of the three orfamide derivatives is similar. Identification of $\mathrm{a}_{1}{ }^{+}, \mathrm{b}_{1}{ }^{+}$and $\mathrm{b}_{2}{ }^{+}$ions confirmed the presence of Leu and Glu in each derivative linked to a specific fatty acid chain, i.e. $\mathrm{C} 12: 0-\mathrm{OH}, \mathrm{C} 14: 1-\mathrm{OH}$ and C14:0-OH for Ofa-D, Ofa-E and Ofa-B respectively. Additional $\mathrm{b}^{+}$ion series that are correlated with the open cycle resulted in identification of the complete peptide chain, as shown in Table 1, and Supporting Information Fig. S5 for Ofa-E (spectra for Ofa-B and Ofa-D not shown). Ions identified as cyclic Val-Leu-Ser-Leu-Leu-Ser $+\mathrm{H}^{+}$were also identified in the ECD spectrum of each orfamide species. Based on these results, we could conclude that the structure of the orfamides from Pseudomonas
CMR12a is very similar to that of the previously characterized lipopeptide produced by the biocontrol strain P. protegens Pf-5 (Gross et al., 2007). More specifically, fraction Ofa-B appears to be identical to orfamide $B$, and was consequently also named orfamide B. However, orfamide D (Ofa-D) and orfamide $E$ (Ofa-E) differ from orfamide $\mathrm{A}$ and $\mathrm{C}$ by the substitution of allo-lle4 by a Val residue, and from orfamide $B$ by modifications of the fatty acid chain.

In silico analysis of sessilin and orfamide synthetases

Analysis of the CMR12a draft genome revealed two large NRPS gene clusters that exhibit several typical features of NRPS genes responsible for CLP biosynthesis, such as the presence of a starter condensation $(C)$ domain and two terminal thioesterase domains (Fig. 2). These sequence data have been submitted to the GenBank databases under accession number JQ309920 and JQ309921 for the NRPS gene clusters and flanking regions of sessilin and orfamide respectively. In each NRPS gene cluster, three large open reading frames (ORFs) could be identified, together spanning a region of 60189 and 34453 base pairs respectively.

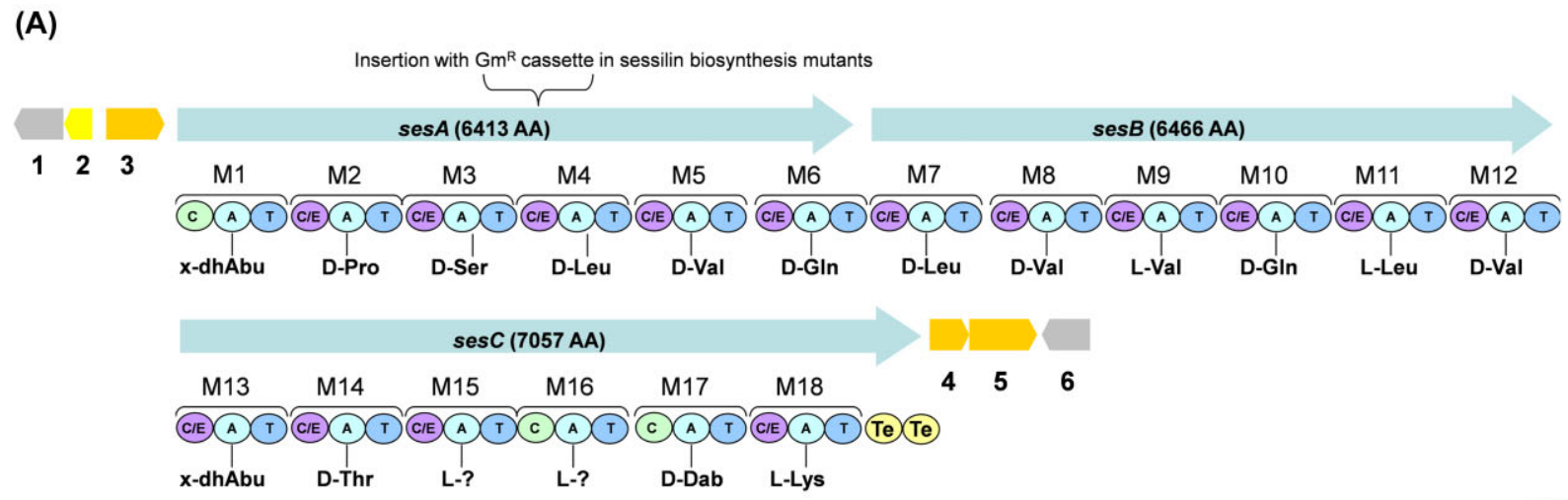

$1000 \mathrm{AA}$

(B)

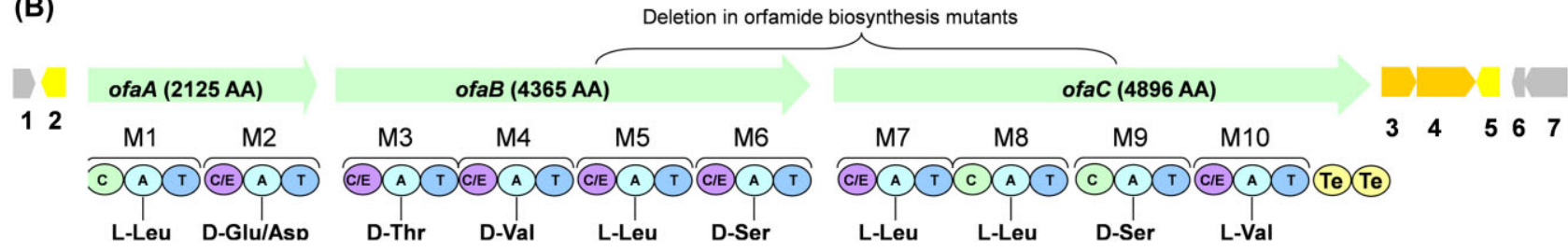

Fig. 2. Putative NRPS gene clusters identified in the genome of CMR12a by in silico analysis. A description of flanking gene similarity and putative function can be found in Table 2 .

A. Gene cluster composed of three NRPS-encoding ORFs, designated sesA, sesB and sesC, responsible for sessilin biosynthesis in CMR12a. B. Gene cluster composed of three NRPS-encoding ORFs, designated ofaA, ofaB and ofaC, responsible for orfamide biosynthesis in CMR12a. Arrows represent ORFs encoding separate NRPSs in each gene cluster. Positions and nature of sessilin and orfamide biosynthesis mutations are indicated. $\mathrm{M}$, module responsible for addition of one amino acid to peptide chain; Te, thioesterification domain. Predicted amino acid specificity, including putative absolute configuration, is shown under each A domain. dhAbu, 2,3-dehydro-2-aminobutyric acid; Thr, threonine; Pro, proline; Ser, serine; Leu, leucine; Asp, asparagine; Val, valine; Gln, glutamine; lle, isoleucine; Dab, 2,4-diaminobutyric acid; Lys, lysine. 
Table 2. Predicted ORF in biosynthesis gene clusters and flanking areas of sessilin and orfamide.

\begin{tabular}{|c|c|c|c|c|}
\hline & & \multicolumn{3}{|c|}{ Similarity } \\
\hline \multicolumn{2}{|c|}{ Putative function } & P. protegens Pf-5 & P. syringae pv. syringae B728a & P. tolaasii PMS117 \\
\hline \multicolumn{5}{|c|}{ Sessilin biosynthesis cluster and flanking area } \\
\hline 1 & $\begin{array}{l}\text { NodT family efflux transporter outer } \\
\text { membrane factor lipoprotein }\end{array}$ & 71\% PFL_2142 & 71\% Psyr_2606 & $\begin{array}{l}\text { 97\% multidrug transporter } \\
\text { WP_016969116.1 }\end{array}$ \\
\hline 2 & LuxR family transcriptional regulator & $56 \%$ PFL_2143 & 49\% Psyr_2607 & $\begin{array}{l}\text { 94\% hypothetical protein } \\
\text { WP_016969117.1 }\end{array}$ \\
\hline 3 & Cyclic peptide transporter & & 70\% Psyr_2613 (syrD) & $\begin{array}{l}\text { 98\% ATP binding protein } \\
\text { WP_016969118.1 }\end{array}$ \\
\hline ses $A$ & Non-ribosomal peptide synthetase & & 58\% Psyr_2614 (sypA) & $\begin{array}{l}\text { 97\% hypothetical protein, partial } \\
\text { WP_016969119.1 }\end{array}$ \\
\hline sesB & Non-ribosomal peptide synthetase & & 58\% Psyr_2615 (sypB) & $\begin{array}{l}96 \% \text { hypothetical protein, partial } \\
\text { WP_016968894.1 }\end{array}$ \\
\hline sesC & Non-ribosomal peptide synthetase & & 57\% Psyr_2616 (sypC) & $\begin{array}{l}\text { 97\% hypothetical protein, partial } \\
\text { WP_017255869.1 }\end{array}$ \\
\hline 4 & Macrolide efflux protein MacA & 81\% PFL_2148 & 72\% Psyr_2617 & $\begin{array}{l}97 \% \text { hemolysin secretion } \\
\text { protein D WP_016971832.1 }\end{array}$ \\
\hline 5 & $\begin{array}{l}\text { Macrolide efflux protein MacB } \\
\text { diaminobutyrate-2-oxoglutarate } \\
\text { transaminase/diadenosine }\end{array}$ & $80 \%$ PFL_2149 & 77\% Psyr_2618 & $\begin{array}{l}99 \% \text { macrolide } A B C \text { transporter } \\
\text { ATP binding protein } \\
\text { WP_016971833.1 }\end{array}$ \\
\hline 6 & Tetraphosphate & & 76\% Psyr_2619 & $\begin{array}{l}\text { 98\% diadenosine } \\
\text { tetraphophatase } \\
\text { WP_016971834.1 }\end{array}$ \\
\hline \multicolumn{5}{|c|}{ Orfamide biosynthesis cluster and flanking area } \\
\hline 1 & Putative (protein) acetyltransferase & $\begin{array}{l}50 \% \text { Brevibacillus } \\
\text { sp. BC25 }\end{array}$ & & \\
\hline 2 & LuxR family transcriptional regulator & $78 \%$ PFL_2143 & & \\
\hline ofaA-12a & Non-ribosomal peptide synthetase & 79\% PFL_2145 (ofaA) & & \\
\hline ofaB-12a & Non-ribosomal peptide synthetase & 82\% PFL_2146 (ofaB) & & \\
\hline ofaC-12a & Non-ribosomal peptide synthetase & 82\% PFL_2147 (ofaC) & & \\
\hline 3 & Macrolide efflux protein MacA & 92\% PFL_2148 & & \\
\hline 4 & Macrolide efflux protein MacB & 91\% PFL_2149 & & \\
\hline 5 & LuxR family transcriptional regulator & 74\% PFL_2150 & & \\
\hline 6 & Glyoxalase family protein & 79\% PFL_2151 & & \\
\hline 7 & $\begin{array}{l}\text { Heme transporter } \mathrm{CcmD} \text {, radical } \\
\text { SAM domain protein }\end{array}$ & 93\% PFL_2152 & & \\
\hline
\end{tabular}

a. From P. tolaasii 6264 .

Annotation was derived from BLAST analysis. Percentage of sequence identity at the amino acid level to the most related genes (based on max score) is shown.

ABC, ATP binding cassette; ATP, adenosine tri-phosphate; Syp, syringopeptin synthetase.

The largest gene cluster (Fig. 2A) contains three NRPS genes $\operatorname{ses} A$, ses $B$ and $\operatorname{ses} C$, which each encode six modules, consisting of a $\mathrm{C}$ or dual C/epimerization $(\mathrm{C} / \mathrm{E})$ domain (see below), adenylation (A) and thiolation ( $\mathrm{T}$ ) domain. At the amino acid level, these genes are related to the syringopeptin encoding genes from Pseudomonas syringae pv. syringae (Scholz-Schroeder et al., 2003) (Table 2). Moreover, they show very high similarity with hypothetical genes from P. tolaasii (Table 2), which may suggest that these hypothetical genes code for tolaasins. The translated sequences of each ORF were studied with online NRPS specificity prediction software, which analyses the A domains, and by phylogenetic analysis of their $C$ domains (see next section). Globally, putative peptide sequences obtained this way are in agreement with the structure derived by chemical analysis of sessilin. However, several ambiguities remained because prediction for module 15 was only indicative of a non-polar monomer, and no reliable prediction could be acquired for module 16, which is in agreement with the chemical analysis that showed a putative relaxed substrate selectivity of module 16, resulting in Hse16 in S-A and Gly16 in $\mathrm{S}-\mathrm{C}$. We assumed that the second NRPS gene cluster (Fig. 2B) encoded the synthetases responsible for orfamide production. This cluster is also composed of three NRPS genes, designated ofaA, ofaB and ofaC. However, they are considerably smaller, containing two, four and again four C-A-T modules respectively. At the amino acid level, these genes show high similarity with the orfamide encoding genes ofaA (PFL2145), ofaB (PFL2146) and ofaC (PFL2147) from P. protegens Pf-5 (Table 2). The predicted peptide chain consists of 10 amino acids and agrees with the results of the chemical structure analysis of orfamide. Interestingly, the in silico sequence analysis confirmed that module 4 of the synthetases favours the incorporation of a Val residue in 
the peptide, while for orfamide from $P$. protegens Pf-5, the prediction indicated that an lle is preferably selected by this module (Gross et al., 2007). Indeed, HPLC analysis of the acid hydrolysate of orfamide $E$ (Supporting Information Fig. S2) detected the presence of Val, but not of lle and in the ECD spectrum the Val residue in the peptide sequence was localized using the $\mathrm{b}_{4}{ }^{+}$fragment ion (Supporting Information Fig. S5).

\section{Phylogenetic analysis of $C$ domains to predict putative absolute configuration}

Because no separate $E$ domains were detected in the synthetases for sessilin and orfamide, we assumed that the incorporation of D-amino acids probably occurs through the action of dual C/E domains, as was described before for CLP synthetases in other pseudomonads (Balibar et al., 2005; De Bruijn et al., 2008; Dubern et al., 2008). It was shown that these dual $C / E$ domains can be distinguished from ordinary $\mathrm{C}$ domains by the presence of specific signature sequences. Therefore, we constructed a phylogenetic tree starting from 91 sequences corresponding to the $\mathrm{C}$ domains of $7 \mathrm{CLPs}$, including 28 sequences implicated in C activity of sessilin and orfamide synthetases (Supporting Information Fig. S6). The phylogenetic analysis is detailed in the supplementary data and points to a putative structure for sessilin with the same absolute configuration as that of tolaasin, while the prediction of the absolute configuration for orfamide of CMR12a is presumably the same as for orfamide of P. protegens Pf-5 (Table 1).

\section{Flanking regions of sessilin and orfamide synthetases}

Overall, flanking regions of the biosynthesis gene clusters for sessilin and orfamide (Fig. 2 and Table 2) are similar to the ones found in the vicinity of CLP biosynthesis genes in other strains and include both putative regulator and transporter genes. In particular, the genes flanking ofaABC in Pseudomonas CMR12a are quite well conserved in comparison with the ones flanking the orfamide biosynthesis genes in P.protegens Pf-5. However, in P. protegens Pf-5, a LuxR-type regulator gene (PFL_2143) upstream of the biosynthesis genes is preceded by a gene encoding a NodT family efflux transporter outer membrane factor lipoprotein (PFL_2142), while in CMR12a, this gene is lacking. Instead, genes showing moderate sequence similarity to unrelated species, i.e. Brevibacillus, Xenorhabdus and Neisseria spp., were found upstream of the LuxR-type regulator gene. Whether these genes are connected with orfamide synthesis was not determined. The flanking genes of ses $A B C$ are analogous to the genes found in the vicinity of the syringomycin-syringopeptin biosynthesis clusters of $P$. syringae, although some of the genes, especially macA and macB, bear a higher similarity to their analogues in $P$. protegens Pf-5. Interestingly, the whole gene cluster shows very high sequence similarity with hypothetical genes of the mushroom pathogen $P$. tolaasii (Table 2) and with whole genome shotgun contigs of the mushroom pathogens $P$. fluorescens NZI7 (contig 00085, 00090 and 00096 in GenBank), P. tolaasii PMS117 (contigs 00008, 00011, 00029, 00123 in GenBank), P. tolaasii NCPPB2192 (SCF_14836_01357 and SCF_ 14836_03198 in GenBank) and P. tolaasii 6264 (contigs 00166, 00245, 00275 and 00828 in GenBank). The upstream region of the sessilin gene cluster contains various integrases and transposases indicating that the cluster is on a chromosomal island and probably obtained by horizontal gene transfer.

\section{Characterization of phenazine, sessilin and orfamide biosynthesis mutants}

Mutants in phenazine production and/or sessilin synthesis were already available (Supporting Information Table S3) (D'aes et al., 2011). The knowledge acquired in this study about the biosynthesis genes for orfamide allowed for the construction of biosynthesis mutants in this CLP. To investigate the importance of phenazines and CLPs for biofilm formation and swarming by CMR12a, four new site-specific mutants in CLP and/or phenazine biosynthesis were created, i.e. an orfamide biosynthesis mutant CMR12a- $\Delta$ Clp2, a double phenazine and orfamide mutant CMR12a- $\Delta \mathrm{Phz}-\Delta \mathrm{Clp} 2$, a double sessilin and orfamide biosynthesis mutant CMR12a- $\Delta$ Clp2-Clp1, and CMR12a- $\Delta$ Phz- $\Delta$ Clp2-Clp1, in which production of all three metabolites was knocked out. LC-ESI-MS analysis of culture extracts confirmed that production of orfamide $\mathrm{B}, \mathrm{D}$ and $\mathrm{E}$ by CMR12a- $\Delta \mathrm{Clp} 2$ and CMR12a- $\Delta \mathrm{Phz}-\Delta \mathrm{Clp} 2$ was completely abolished. Mutants CMR12a- $\Delta$ CLP2Clp1 and CMR12a- $\Delta$ Phz- $\Delta$ Clp2-Clp1 produced neither sessilin nor orfamide (Supporting Information Fig. S7). In addition, HPLC on culture extracts (results not shown) confirmed that all mutants with a deletion in the phenazine biosynthesis operon no longer produced any phenazines. We demonstrated before that the sessilin mutant CMR12a-Clp1 makes markedly more phenazines than the wild type (D'aes et al., 2011), although at this point we can only speculate about the mechanism involved in this phenomenon. Overproduction of phenazines was not observed for the other biosynthesis mutants (data not shown). We did not observe noticeable growth defects (based on optical density measurements and growth rate) on complex media such as Luria-Bertani (LB) or KB broth or defined media such as M9 mineral medium with different carbon sources caused by the mutations in phenazine, sessilin or orfamide production (data not 
shown), indicating that these metabolites have no marked role for primary metabolism in vitro.

\section{Swarming by CMR12a requires orfamide}

The importance of sessilin and orfamide for swarming was investigated via surface motility assays on standard succinate medium (SSM) and modified LB (MLB) medium with low agar content (0.6\% agar) (Fig. 3).

The wild type CMR12a did not exhibit swarming on SSM (Fig. 3A), although this medium was used to demonstrate swarming by other Pseudomonas strains, such as P. fluorescens SS101 (De Bruijn et al., 2008). On MLB medium, moderate swarming of the wild-type strain Pseudomonas CMR12a started after $24 \mathrm{~h}$ (Fig. 3B) and was more noticeable at $48 \mathrm{~h}$ (Supporting Information Fig. S8). However, sessilin biosynthesis mutants showed swarming on both media. Orfamide production is required for the swarming ability of CMR12a because swarming was completely abolished on both media in all orfamide biosynthesis mutants.

LC-ESI-MS analysis revealed the presence of both CLPs in wild-type cells grown on MLB medium or SSM, indicating that the inability to swarm is not due to the absence of orfamide (Fig. $3 \mathrm{C}$ and D). These analyses also showed that the improved swarming of the CMR12aClp1 mutant does obviously not result from a higher production of orfamide compared with wild-type cells (Fig. 3C and D). For complementation assays, mutant strains were co-cultured with the wild-type strain or with each other on SSM and MLB medium. Remarkably, swarming of the sessilin mutant CMR12a-Clp1 was abolished in the presence of the wild-type ( $\mathrm{B}+\mathrm{A}$ in Fig. 3 ) or CMR12a- $\Delta \mathrm{Clp2}$ mutant ( $B+C$ in Fig. 3). LC-ESI-MS analysis revealed that under these conditions, orfamides are still produced (Fig. $3 \mathrm{C}$ and D). Moreover, the orfamide-deficient mutants CMR12a- $\Delta$ Clp2 and CMR12a- $\Delta$ Clp2-Clp1 double mutant could be complemented for swarming by supplying a semi-purified orfamide extract or orfamide-containing supernatant from CMR12a-Clp1 to MLB medium (Supporting Information Figs S8 and S9). Sessilin-containing supernatant from the CMR12a- $\Delta$ Clp2 mutant slightly diminished swarming of the wild type on MLB medium, but was unable to stop swarming of the CMR12a-Clp1 mutant (Supporting Information Fig. S9).

\section{Sessilin but not orfamide is involved in biofilm formation by CMR12a}

Biofilm formation by CMR12a and its mutants was tested in polystyrene 96-well plates filled with $A B$ broth amended with $2 \%$ casamino acids, similar to a method described by Maddula and colleagues (2006). With this set-up, CMR12a forms biofilms at the interface between air and liquid. Figure 4A displays the development of biofilms by CMR12a and its mutants. Growth speed and maximal cell densities were comparable with that of the wild-type strain for all the mutants under these conditions. Remarkably, sessilin mutants formed markedly less biofilm in the plates. Phenazines appeared to play a limited role in biofilm formation by CMR12a, while the mutant in orfamide biosynthesis (CMR12a- $\Delta$ Clp2) produced more biofilm than the wild type. Interestingly, mutations were able to (partially) compensate each other if causing contrasting effects. For example, the amount of biofilm formed by CMR12a- $\Delta \mathrm{Clp} 2-\mathrm{Clp} 1$ was intermediary between that of the wild type and CMR12a-Clp1.

LC-ESI-MS profiling of the lipopeptides produced by the wild type under biofilm-forming conditions revealed an efficient production of sessilins (Fig. 4B). However, no orfamide could be detected in the culture filtrate (below detection limit). When grown in the same medium but in agitated flask cultures, CMR12a formed more biomass (data not shown), but cells remained planktonic and production of sessilin was clearly reduced compared with biofilm-forming conditions as illustrated in Fig. 4B.

\section{Sessilin and orfamide interact to form a white line precipitate}

Sessilin is related to tolaasin, produced by the mushroom pathogen $P$. tolaasii. Since it is known that tolaasin can co-precipitate with white line-inducing principle (WLIP) (Wong and Preece, 1979), a viscosin-related CLP produced by Pseudomonas 'reactans' NCPPB 387 we tested the ability of sessilin to form a white-line-in-agar reaction with WLIP and other CLPs. In the experiment depicted in Fig. 5, which was performed on KB agar medium, the CMR12a strain and its three CLP mutants were confronted to each other and to four other Pseudomonas isolates with specific CLP signatures. These experiments revealed that the wild-type strain Pseudomonas CMR12a (1) shows a white-line-in-agar reaction with mutant CMR12a-Clp1 (2), which only produces orfamides, but not with the mutant CMR12a- $\Delta$ Clp2 (3), which only produces sessilins, or mutant CMR12a- $\Delta$ Clp2-Clp1 (4), which does not produce CLPs. Mutant CMR12a-Clp1 (2), however, forms a white line reaction with CMR12a (1) and mutant CMR12a- $\Delta$ Clp2 (3). The tolaasin-producing mushroom pathogen $P$. tolaasii (5), forms a white-line-in-agar with WLIP produced by P. 'reactans' NCPPB 387 (6), and this is also the case for the sessilin producers Pseudomonas CMR12a (1) and CMR12a- $\Delta$ Clp2 (3). Moreover, a clear white line reaction was also observed between sessilin producers and the orfamide-producing strain P. protegens Pf-5 (7), but not with the massetolide producing strain $P$. fluorescens R1SS101 (8). From these experiments, it can be concluded that, although the 

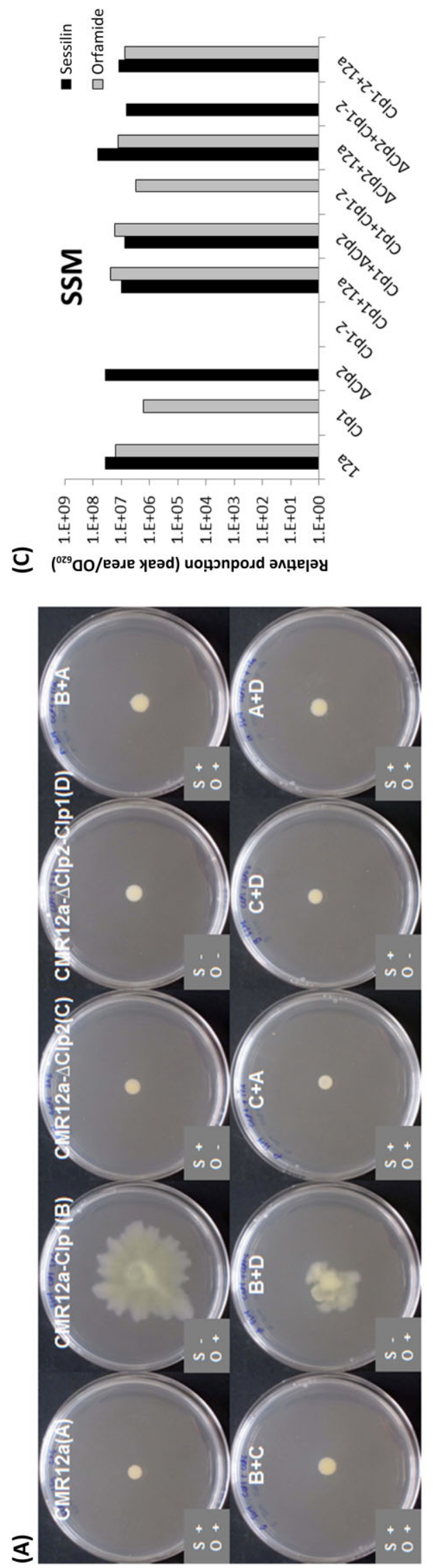
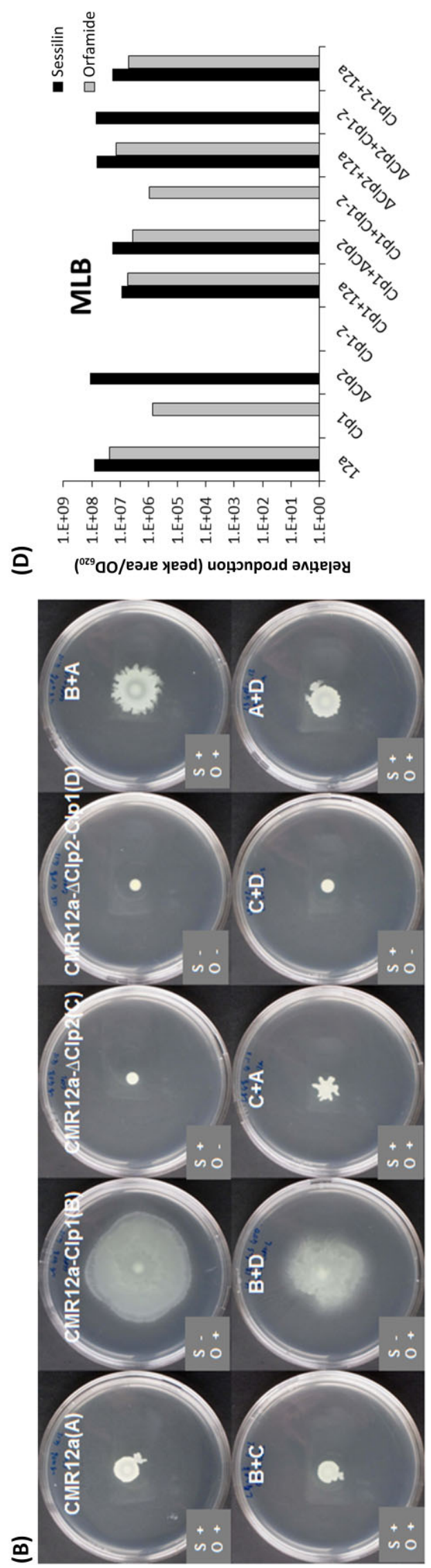

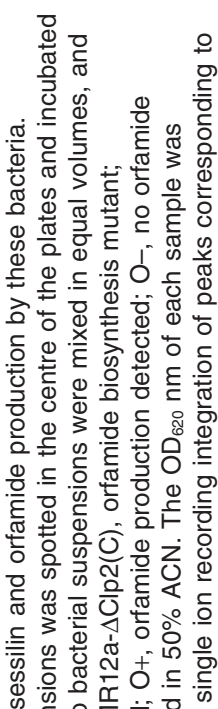

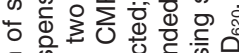
드월

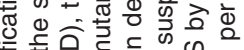

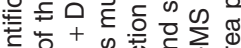

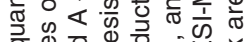

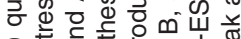
口言

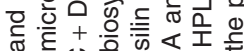

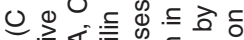

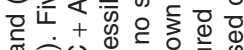

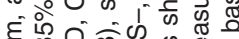

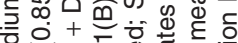
o 0 응 $\frac{\pi}{2}$ o

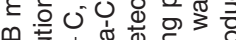

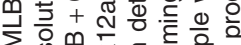

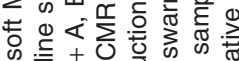
$\widehat{0} \omega$ 造

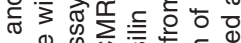

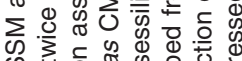
क立

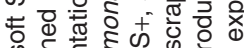
का उ3 ᄃ 䎹

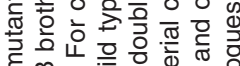
ह 可.

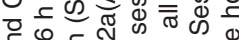

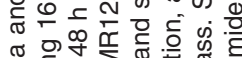

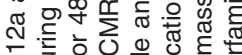
뜬

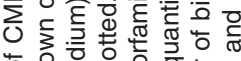

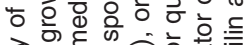

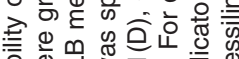

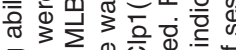
잉 0 है

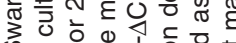
क क는 门

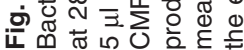




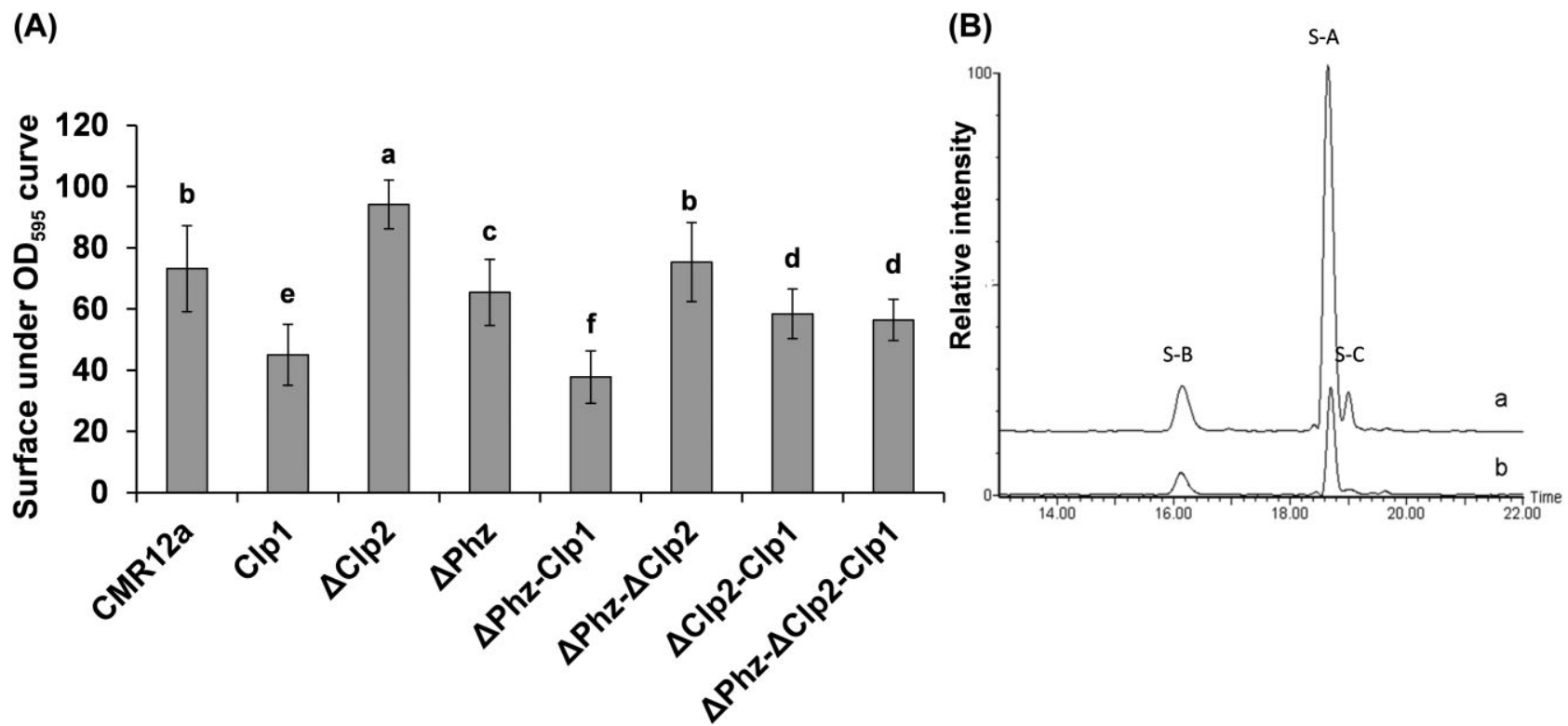

Fig. 4. A. Biofilm formation capacity of CMR12a and its phenazine and CLP mutants. The $y$-axis represents the surface under the curve obtained for measurements in time of crystal violet solutions at $595 \mathrm{~nm}$, which are directly proportional to development of biofilms. Experiments were repeated at least once, and each time 11 replicates per treatment were used. Means of two experiments are shown. Different letters indicate significantly different treatments $(\alpha=0.05)$. Vertical bars indicate standard deviations. $\Delta$ Phz, phenazine biosynthesis mutant; CLP1, sessilin biosynthesis mutant; $\triangle \mathrm{CLP} 2$, orfamide biosynthesis mutant.

B. LC-ESI-MS chromatogram showing sessilin production by CMR12a in AB + casamino acids medium. a, biofilm forming cells in liquid medium (in 96-well plates); b, planktonic cells in liquid medium (agitated flask cultures).

wild-type strain Pseudomonas CMR12a produces both sessilins and orfamides on KB medium (see Fig. 1), only sessilin is released in the KB agar medium, while orfamides are either not secreted or retained close to the cell wall. The sessilin mutant CMR12a-Clp1, however, readily releases orfamides in the medium. Matrix assisted laser desorption/ionisation time-of-flight mass spectrometry (MALDI-ToF MS) analysis of lipopeptides present in $\mathrm{KB}$ agar medium during interaction between CMR12a$\triangle$ CLP2 and CMR12a-CLP1 confirmed that both orfamide and sessilin accumulate in the zone corresponding to the white line, strongly suggesting that the two compounds interact to form a precipitate (see Supporting Information Fig. S10 for details).

\section{Discussion}

Pseudomonas CMR12a produces two different classes of CLPS

Our study revealed that Pseudomonas CMR12a produces two different classes of CLPs, which display specific structural features but are related to previously described CLPS, namely tolaasins and orfamides.

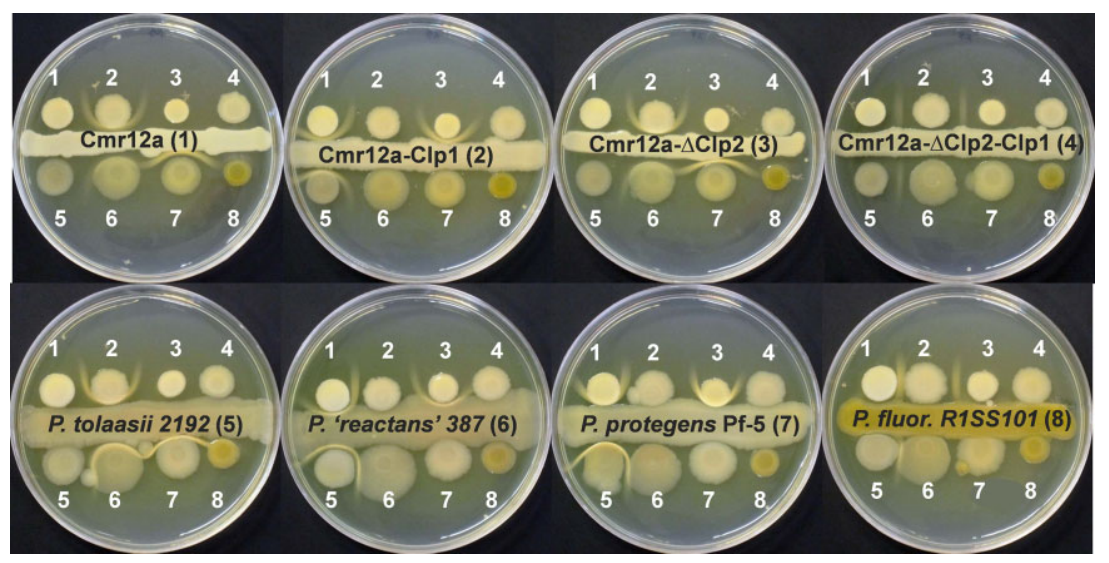

Fig. 5. White-line formation obtained by confronting various CLP producing Pseudomonas strains on KB medium. Picture was taken after 6 days incubation at $28^{\circ} \mathrm{C}$. Strains used: (1) Pseudomonas sp. CMR12a; (2) CMR12a-Clp1; (3) CMR12a- $\Delta$ Clp2; (4) CMR12a- $\Delta$ Clp2-Clp1; (5) P. tolaasii NCPPB 2192; (6) P. 'reactans' NCPPB 387; (7) $P$. protegens Pf-5; (8) P. fluorescens R1SS101. See Supporting Information Table S3 for strain characteristics. 
The first class of CLPs secreted by CMR12a, which were designated sessilins, can be classified in the tolaasin group of Pseudomonas lipopeptides. Tolaasins are produced by mushroom pathogens such as P. tolaasii and P. fluorescens NZI7 (Burlinson et al., 2013). But this group also contains fuscopeptin and corpeptin isolated from plant pathogenic pseudomonads (Gross and Loper, 2009). In fact, the main sessilin derivative from CMR12a differs only by one amino acid from tolaasin I, the most abundant form of tolaasin (Bassarello et al., 2004). Our analysis indicated that CMR12a also produces a putative acyclic derivative of sessilin, designated $\mathrm{S}-\mathrm{B}$, together with a third form in which Hse16 is replaced by a Gly residue, and which was named S-C. The presence of these derivatives might explain the ambiguous results obtained by in silico analysis of the sessilin biosynthesis genes. Indeed, the specificity of modules 15 and 16 could not be predicted, probably because they might be somewhat flexible towards the nature of the amino acid residues they can bind. It also seems clear that S-A is the preferred derivative synthesized by CMR12a. However, it is possible that culture and environmental conditions influence the ratio of the different derivatives produced. The tolaasinencoding genes of $P$. tolaasii and $P$. fluorescens NZI7 have not been annotated, but the sessilin biosynthetic genes and surrounding genes show very high similarity (about $94 \%$ at the nucleotide level) with hypothetical genes on whole genome shotgun contigs of $P$. tolaasii (various strains) and $P$. fluorescens NZI7 (Burlinson et al., 2013). It indicates that these genes most likely are responsible for tolaasin biosynthesis and secretion. This high level of similarity is striking because Pseudomonas CMR12a and P. tolaasii are relatively distantly related with a level of similarity for housekeeping genes such as gyrB, rpoB and recA around 88-91\%. The presence of transposases and integrases upstream of the sessilin gene cluster indicates that these genes are located on a genomic island that Pseudomonas CMR12a has acquired by horizontal gene transfer (Juhas et al., 2009).

The second group of CLPs produced by CMR12a were identified as very similar to orfamide produced by the biocontrol strain P. protegens Pf-5 (Gross et al., 2007). These three orfamide derivatives were analysed structurally, which were designated orfamide $B, D$ and $E$ respectively. However, they still differ from orfamides regarding the fatty acid chain length and saturation, and by the absence of an lle4 residue in the peptide backbone. The identity at amino acid level between both orfamide biosynthesis gene clusters is only around $80 \%$, while at nucleotide level the similarity varies from $80 \%$ to $84 \%$ identity. This similarity is rather low because Pseudomonas CMR12a and P. protegens Pf-5 are closely related, and their housekeeping genes such as $r p o B$, gyr $B$ and recA show a similarity of $92-94 \%$. Moreover, results from in silico prediction of the amino acid residues show that the fourth module in the orfamide synthetase from Pf-5 activates an isoleucine residue instead of a valine residue in orfamide from Pseudomonas CMR12a, indicating that the catalytic domains differ significantly at this site.

CLPs are secreted by $A B C$ transporters similar to the Echerichia coli macrolide efflux transporter MacAMacB-TolC. Genes potentially involved in orfamide secretion (MacA and MacB) and regulation (LuxR regulators) are found downstream of the orfamide biosynthetic genes and are conserved at the amino acid level between Pf-5 and CMR12a. The TolC equivalent is presumably encoded by the Pfl_2142 gene in $P$. protegens Pf-5. It is annotated as a NodT family efflux transporter and precedes the gene encoding the LuxR transcriptional regulator upstream of the orfamide biosynthesis genes in Pf-5. This genomic organization of transporter genes is similar in various Pseudomonas CLP gene clusters (De Bruijn et al., 2008; Dubern et al., 2008; Vallet-Gely et al., 2010; Rokni-Zadeh et al., 2012; Li et al., 2013). However, the involvement of the putative NodT efflux transporter in CLP efflux has to our knowledge not been experimentally shown. Interestingly, there is no homologue of Pfl_2142 in the orfamide gene cluster of Pseudomonas CMR12a, but its closest homologue in the Pseudomonas CMR12a genome is found upstream of the sessilin gene cluster (Table 2).

So far, simultaneous production of two different classes of CLPs by one strain has only been demonstrated for plant-pathogenic pseudomonads. The reason for this phenomenon is not clear, but several authors have already suggested that in these cases one CLP could have surfactant-like activity, while the other CLP would be rather toxin-like, resulting in a synergistic effect with increased virulence towards the host plant (lacobellis et al., 1992; Batoko et al., 1998; Bender et al., 1999). However, our strain clearly displays plantbeneficial properties, implying a different biological role for its CLPs as compared with plant-pathogenic species. Sessilin is implicated in the biocontrol of $R$. solani and other fungal pathogens and strongly inhibits their growth in vitro (D'aes et al., 2011). Pure tolaasin I, produced by $P$. tolaasii NCPPB2192, inhibits the growth of edible fungi such as Agaricus bisporus, Lentinus edodes and Pleurotus spp. (Lo Cantore et al., 2006). These results indicate that both $P$. tolaasii and biocontrol agents such as Pseudomonas spp. CMR12a can be considered as fungal pathogens. It would be worthwhile to investigate whether tolaasin-producing mushroom pathogens such as $P$. tolaasii and $P$. fluorescens NZI7 also produce a 
second CLP and whether they have biocontrol activities when applied to plant roots. In this context, it is noteworthy that the genome of $P$. fluorescens NZI7 is very similar to that of the biocontrol agent P. protegens Pf-5 (Burlinson et al., 2013).

Sessilins and orfamides are differentially involved in biofilm formation and swarming

The fact that CMR12a produces at least two CLPs as well as two phenazine derivatives must imply a particularly important role for these molecules in the survival of CMR12a in its natural niche. Biosynthesis mutants in phenazines, sessilin and/or orfamide were shown to grow adequately in vitro. However, in a natural environment, bacterial cells typically exist as biofilm communities. In addition, the ability to migrate on a surface provides an advantage in order to locate new nutrient-rich habitats (Verstraeten et al., 2008). Some studies already demonstrated that CLPs are of essential importance for the formation of biofilms and for swarming motility (Raaijmakers et al., 2010). Here, we showed that a sessilin mutation caused a drastically reduced capacity for biofilm formation on a hydrophobic surface, while orfamide biosynthesis mutants showed increased biofilm formation, indicating that sessilins are crucial for biofilm formation in Pseudomonas CMR12a. Phenazines have been shown to influence biofilm formation as well (Maddula et al., 2006; 2008; Ramos et al., 2010; Selin et al., 2010), but these compounds have only a limited (albeit significant) influence on biofilm formation by CMR12a. This effect is actually much less pronounced than for P. chlororaphis 30-84, in which case biofilm formation capacity is strongly reduced in a phenazine biosynthesis mutant (Maddula et al., 2006).

Orfamide biosynthesis mutants completely lost their swarming ability, which could be restored by adding a crude orfamide extract to the swarming plates. These data confirm the observations of Gross and colleagues (2007), showing that orfamide is also required for swarming by P. protegens Pf-5. Other CLPs with activity similar to that of orfamide have already been characterized, for example putisolvin and arthrofactin, produced by P. putida PCL1445 and Pseudomonas sp. MIS38 respectively (Roongsawang et al., 2003; Kuiper et al., 2004).

A remarkable result of the swarming assays was the inability of CMR12a to swarm on SSM and the retarded swarming on MLB medium, which is not due to the absence of orfamides, because the molecules could readily be detected in cells grown on these two media. Unlike the wild type, the sessilin biosynthesis mutant CMR12a-CLP1 was no longer prevented from swarming on these media.
The interplay between sessilins and orfamides determines whether Pseudomonas CMR12a cells settle or move

Our data suggest that the presence of sessilin interferes with swarming activity in two different ways. As has been shown before for tolaasins and WLIP (Wong and Preece, 1979), sessilins and orfamides chemically interact and co-precipitate with each other to form a white line in agar. In addition, the white line assays suggest that the presence of sessilin in Pseudomonas CMR12a interferes with the release of orfamides in the medium.

It is interesting to notice that tolaasins and sessilins not only form a white line with WLIP, a CLP belonging to the viscosin group (Rokni-Zadeh et al., 2013), but also with orfamides. The white line reaction was thought to be structure specific for WLIP and strains able to produce WLIP used to be grouped as $P$. 'reactans' and are commonly used in diagnostic tests to identify tolaasin producers. Rokni-Zadeh and colleagues (2013), however, recently showed that various $P$. fluorescens and $P$. putida strains are able to produce WLIP, urging the discontinuation of the use of the invalid species designation $P$. 'reactans'. Intriguingly, not only WLIP, but also orfamides trigger the white line reaction with tolaasins and sessilins, while CLPS which are more closely related to WLIP such as viscosin (Rokni-Zadeh et al., 2013) and massetolide (Table 1) do not trigger such reaction. This definitely warrants further investigation. The interaction between the two CLPs probably explains why in the complementation assays on swarming medium, the swarming of sessilin mutants can be blocked by sessilin producers such as the wild-type strain or orfamide mutants. It should be noted, however, that we were unable to block the motility of the sessilin mutants by adding sessilincontaining supernatant from mutant CMR12a-Clp2.

The white line assays revealed that release of orfamide in the environment is hampered in the presence of sessilins, either because orfamide is retained within the cytoplasm or periplasm or stays closely associated with the cell surface. In this context, it is interesting to recall that the orfamide gene cluster in Pseudomonas CMR12a is not preceded by a NodT family efflux transporter. One possible explanation could be that the MacA-MacB transporters of sessilin and orfamide make use of the same outer membrane efflux transporter upstream of the sessilin biosynthetic cluster. Further investigation is needed to find out whether competition for the outer membrane protein could explain the negative effect of sessilin on orfamide secretion. We speculate at this point that sessilin might act as a signal molecule involved in fine tuning the balance between biofilm formation and surface motility in response to environmental cues. Such cues could be nutrient limitation or stress conditions, but this 
requires further study. It is not unlikely that CLPs act as signal molecules. A study by López and colleagues (2009) pointed to a regulatory role for surfactin, a CLP produced by Bacillus subtilis, in biofilm formation. Apparently, surfactin influenced the activity of ion channels, causing potassium leakage from the cytoplasm. Potassium leakage stimulated the activity of a membrane protein kinase, which governed the expression of genes involved in biofilm formation. As tolaasin has been described to form cation-selective ion channels in planar lipid bilayer (Brodey et al., 1991), such a mechanism could be evoked to explain the role of sessilin in biofilm formation.

The question remains why sessilins and orfamides exhibit such divergent biological activity. Raaijmakers and colleagues (2010) discuss the influence on biofilm formation of hydrophobicity and charge of the lipopeptide, its orientation towards the bacterial cells, as well as environmental conditions. Furthermore, the length of the fatty acid chain and composition of the peptide moiety can be a crucial determinant of CLP activity (Morikawa et al., 2000; Jourdan et al., 2009). This might explain some of the differences between both metabolites as sessilins harbour a rather short (C8) and orfamides a long (C12 or C14) fatty acid moiety.

\section{Regulation of CLP production in Pseudomonas CMR12a}

Presently, little information is available about regulation of sessilin and orfamide production by CMR12a. We know that the GacS/GacA two-component system controls synthesis of both CLPs (D'aes et al., 2011). Inspection of the flanking regions of sessilin and orfamide synthetase genes revealed several LuxR-type regulator genes, which are typically found in the vicinity of CLP biosynthesis gene clusters. In other Pseudomonas strains, these LuxR-type proteins are involved in regulation of CLP production (De Bruijn and Raaijmakers, 2009); thus, it might be assumed that they fulfil a similar role in the regulation of orfamide and sessilin synthesis. This, however, needs further investigation. The two quorum-sensing systems of Pseudomonas CMR12a also appear to be involved in CLP regulation, albeit in an indirect way (N. P. Kieu, unpubl. data).

\section{Pseudomonas CLPS and biocontrol}

With regard to the multifunctionality of phenazines and CLPs in other strains, it is likely that these metabolites still have other parts to play in the cell physiology of CMR12a. Previously, we proved that sessilin is involved in biocontrol of root rot on bean caused by $R$. solani, presumably because of its direct antimicrobial activity. We showed that sessilin strongly suppresses $R$. solani growth, and microscopic observations revealed that CMR12a causes branching of $R$. solani mycelium, while a sessilin biosynthesis mutant loses this ability (D'aes et al., 2011). In vitro assays with biosynthesis mutants indicated that sessilin also inhibits growth of other pathogens, for example P. myriotylum, Pythium splendens and Fusarium oxysporum f. sp. lycopersici (unpublished). Furthermore, preliminary experiments suggest that sessilin induces dark-brown lesions on mushrooms (data not shown), similar to the effects ascribed to tolaasin (Hutchison and Johnstone, 1993). The results described in this paper shed new light on the biological activity of sessilin by pointing to an important role in maintaining a balance between biofilm formation and motility. This biological role might also explain part of the importance of sessilin for the biocontrol ability of CMR12a because establishment of a rhizosphere population is a prerequisite for biocontrol agents (Dutta and Podile, 2010). However, to further elucidate the mechanisms involved in the biological activity of sessilin, much more work will be necessary.

The significance of orfamides for the biocontrol properties of CMR12a is still being investigated at present. Preliminary data suggest that the direct antagonistic properties of orfamides are not as pronounced as those of sessilin, but that orfamides are essential for biocontrol activity in vivo (data not shown). It is likely that its observed role in swarming will also affect the rhizosphere competence of CMR12a. However, it is not sure how effects of phenazines and CLPs on biofilm formation and swarming observed in vitro can be extrapolated to root colonization. Barahona and colleagues (2010) showed that $P$. fluorescens mutants deficient for biofilm formation on abiotic surfaces colonized alfalfa roots as efficiently as the wild-type strain. Our results (D'aes et al., 2011) indicated that phenazine, sessilin and orfamide mutants can still colonize roots, but the observations were based on short-term colonization experiments and were not always consistent. More in-depth study will be required to assess whether orfamides for instance could be involved in spreading of the bacteria to more distal parts of the roots, while sessilin and/or phenazines could be required to maintain developed microcolonies on the root surface for longer periods.

\section{Experimental procedures}

\section{Strains and culture conditions}

Strains, plasmids and primers used in this study are listed in Supporting Information Table S3. Pseudomonas sp. CMR12a was grown on KB (King et al., 1954) at $28^{\circ} \mathrm{C}$. Echerichia coli strains were cultivated on LB medium (Sambrook et al., 1989) at $37^{\circ} \mathrm{C}$, and Saccharomyces cerevisiae InvSc1 at $30^{\circ} \mathrm{C}$ on yeast extract-peptone-dextrose (Shanks et al., 
2006). When required, gentamicin was added at a concentration of $25 \mu \mathrm{g} \mathrm{ml}^{-1}$ for E. coli strains and at $300 \mu \mathrm{g} \mathrm{ml}^{-1}$ for Pseudomonas CMR12a and mutant strains.

\section{Analysis of CLPS by LC-ESI-MS}

Crude extracts were prepared by collecting cells from fully covered KB plates in distilled water, followed by centrifugation, filter sterilization of the supernatant and concentration by lyophilization if required. To screen for high molecular weight compounds potentially representing CLPs, the extracts were analysed by reverse-phase LC-ESI-MS (HPLC Waters Alliance 2695/diode array detector, coupled with Waters SQD mass spectrometer) on an X-terra MS C18 column (100*4.6 mm, $3.5 \mu \mathrm{m}$, Waters), as described before (D'aes et al., 2011). For structural analysis of CLPs by LC-ESI-MS, HPLC purified samples (see below) were injected under the same HPLC conditions, but MS settings used to optimize in-source fragmentation were as follows: positive ion mode, source temperature of $130^{\circ} \mathrm{C}$, desolvation temperature of $280^{\circ} \mathrm{C}$, nitrogen flow of $550 \mathrm{I} \mathrm{h}^{-1}$ and cone voltage of $100 \mathrm{~V}$.

\section{Purification of CLPs by semi-preparative HPLC}

For purification of the CLP-containing fractions, the crude extract was subjected to repeated injections with an Agilent 1100 series HPLC (Hewlett Packard) on a VYDAC 8 C18 reversed-phase 218TP5 column suitable for separation of small polypeptides less than 4000-5000 MW (5 $\mu \mathrm{m}$, $4.6 \mathrm{~mm} \times 250 \mathrm{~mm}$ ). Metabolites were eluted with a gradient of acetonitrile (ACN) acidified with $0.1 \%$ formic acid (eluent $B$ ) in water acidified with $0.1 \%$ formic acid (eluent A) at a constant flow rate of $1 \mathrm{ml} \mathrm{min}{ }^{-1}$ and at room temperature. The gradient programme lasted $45 \mathrm{~min}$, starting at $30 \% \mathrm{~B}$ during $5 \mathrm{~min}$, rising to $51 \% \mathrm{~B}$ in $5 \mathrm{~min}$, further to $65 \% \mathrm{~B}$ in the following $10 \mathrm{~min}$ and on to $70 \%$ during a $12 \mathrm{~min}$ step. Eluent B was kept at $70 \%$ during $5 \mathrm{~min}$, lowered again to $30 \%$ over $0.5 \mathrm{~min}$ and equilibrated during $7.5 \mathrm{~min}$. The UV signal was monitored at $220 \mathrm{~nm}$. All different fractions were collected and concentrated using rotavaporation and vacuum speed.

\section{Quantitative amino acid analysis}

For amino acid analysis, HPLC-purified compounds were collected in glass tubes and dried using vacuum speed (Speed-Vac Plus SC110A; Savant). One and a half millilitres of $6 \mathrm{~N} \mathrm{HCl}$ was added to the glass tubes, which were subsequently sealed under vacuum. Samples were hydrolysed at $115^{\circ} \mathrm{C}$ during $6 \mathrm{~h}$. After drying in the Speed-Vac, and dissolving in $100 \mu \mathrm{l}$ of $0.1 \mathrm{~N} \mathrm{HCl}$, the samples were analysed on a ZORBAX Eclipse AAA column (Agilent) using a Agilent 1100 series HPLC (Hewlett Packard) by strictly following the instructions provided by the Agilent manufacturer. Briefly, the hydrolysed samples and amino acid standard solutions were automatically derivatized in the autosampler with o-phthalaldehyde (OPA) for most amino acids and 9fluorenylmethyl-chloroformate (FMOC) for lysine, hydroxyproline and proline residues. After derivatization, $0.5 \mu \mathrm{l}$ of each sample was injected with a flow rate of $2 \mathrm{ml} \mathrm{min}^{-1}$ and detected at $338 \mathrm{~nm}$ (OPA) and $262 \mathrm{~nm}$ (FMOC). Solution A was $40 \mathrm{mM} \mathrm{NaH} \mathrm{PO}_{4}$, adjusted to $\mathrm{pH} 7.8$ with $\mathrm{NaOH}$, while solution B was ACN/methanol/water (45/45/10 v/v/v). The gradient programme allowed for $1.9 \mathrm{~min}$ at $0 \% \mathrm{~B}$, followed by an 18.1 min step that raised eluent B to $57 \%$. Subsequent washing at $100 \% \mathrm{~B}$ and equilibration at $0 \% \mathrm{~B}$ was performed in a total analysis time of $26 \mathrm{~min}$. Amino acids in the lipopeptide hydrolysis products were identified based on amino acid standards analysed simultaneously.

\section{Accurate mass measurements and structural identification by FT-ICR mass spectrometry}

Prior to further analysis, CLP fractions separated by semipreparative HPLC were submitted to supplementary desalting via nanochromatography (Ultimate LC system, Dionex, LC-Packings, Amsterdam, the Netherlands). Starting from a volume of $1 \mu \mathrm{l}$ of CLP fractions, peptides were desalted using a Pepmap C18 column $(15 \mathrm{~cm} \times 75 \mu \mathrm{m}$; Thermo Scientific) at $200 \mathrm{nl} \mathrm{min}{ }^{-1}$ solvent flow. Elution was performed with gradients of solvent $\mathrm{A}\left(95 \% \mathrm{H}_{2} \mathrm{O}, 5 \% \mathrm{ACN}\right.$ and $0.1 \%$ $\mathrm{HCOOH})$ and solvent $\mathrm{B}\left(25 \% \mathrm{H}_{2} \mathrm{O}, 75 \% \mathrm{ACN}\right.$ and $0.1 \%$ $\mathrm{HCOOH}$ ): $6 \mathrm{~min}$ in $100 \%$ solvent $A$, then solvent $B$ was increased to $50 \%$ over $15 \mathrm{~min}$, kept at $50 \%$ during $10 \mathrm{~min}$, then solvent B was increased to $75 \%$ over $10 \mathrm{~min}$, and to $100 \%$ over $5 \mathrm{~min}$ during $15 \mathrm{~min}$. Finally, solvent B was decreased to $0 \%$ in $5 \mathrm{~min}$. The column was allowed to equilibrate for $15 \mathrm{~min}$. The fractions containing sessilin and orfamide were collected during $100 \%$ B elution. Subsequently, samples were concentrated six times before analysis and placed in $75 \%$ ACN solution acidified with $0.1 \%$ formic acid. The analyses were performed using an Apex Qe 9.4 T Fourier Transform Ion Cyclotron Resonance mass spectrometer (Bruker Daltonics, Bremen, Germany). The FT-ICR mass spectrometer was equipped with a nanoelectrospray source. Detection was carried out in positive mode. A potential of $1.6 \mathrm{kV}$ was applied to the needle (PicoTip Emitter, New Objective, Woburn, MA, USA). Detection parameters were as follows: broadband detection, $512 \mathrm{~K}$ acquisition size, start mass at $\mathrm{m} / \mathrm{z} 500$ for MS spectra and 200 for ECD spectra. Ions were accumulated in the storage hexapole during $1 \mathrm{~s}$ and in the second hexapole during $0.01 \mathrm{~s}$. Parameters used for ECD experiments were ECD pulse $0.03 \mathrm{~s}$, bias $2.0 \mathrm{~V}$, heater $20 \mathrm{~V}$ and cathode current $1.5 \mathrm{~A}$. Spectra were manually processed using DATAANALYSIS software (Bruker Daltonics, Bremen, Germany).

\section{Sequencing and analysis of CMR12a CLP biosynthesis genes}

Whole-genome sequencing of a genomic DNA sample of CMR12a was performed with a Genome Sequencer FLX (Roche 454) by NXTGNT (Gent, Belgium). Draft genome assemblies were achieved with two de novo assemblers, namely MIRA (Chevreux et al., 1999) and VELVET (Zerbino and Birney, 2008). Preliminary structural analysis results showed that CMR12a produces two distinct lipopeptides, most resembling orfamide from $P$. protegens $\mathrm{Pf}-5$ and tolaasin from $P$. tolaasii respectively (D'aes et al., 2011). Syringopeptin is 
the CLP most related to tolaasin for which the biosynthesis gene cluster has been sequenced completely. Therefore, the genome alignment program MAUVE (Darling et al., 2004) was used to order the contigs from the MIRA CMR12a draft genome according to the P. protegens Pf-5 (Paulsen et al., 2006) and P. syringae pv. syringae B728a (Feil et al., 2005) genomes. Putative NRPS clusters derived this way were subsequently completed and validated by identification of contig overlaps and comparison with the Velvet assembly. Additional Sanger sequencing (LGC Genomics) was performed to resolve ambiguous nucleotides and fill small gaps. Putative ORFs were identified with GLIMMER (Delcher et al., 2007). The resulting putative protein sequences were analysed with online NRPS specificity prediction software, namely 'NRPSPREDICTOR' (Rausch et al., 2005). Sequence similarity analysis and gene annotation of NRPS ORFs and flanking genes was performed by BLASTX analysis on NCBI.

\section{Phylogenetic analysis of $C$ domains}

The sequences of all $C$ domains were analysed to distinguish between domains harbouring conventional $C$ activity (C domains) and those displaying dual CE activity (dual C/E domains) (Roongsawang et al., 2005; Rausch et al., 2007). The protein sequences corresponding to these domains were extracted using the PKS/NRPS analysis tool (Bachmann and Ravel, 2009) and aligned with related sequences found in known CLP synthetases. NRPSs responsible for the synthesis of arthrofactin (ArfA, ArfB and ArfC) (Balibar et al., 2005), massetolide (MassA, MassB and MassC) (De Bruijn et al., 2008), orfamide (OfaA, OfaB and OfaC) (Gross et al., 2007), syringopeptin 22A (SypA, SypB and SypC) (Scholz-Schroeder et al., 2003) and syringomycin (SyrE) (Singh et al., 2007) were included in the analysis. One supplementary synthetase for putisolvin (PsoA, PsoB and PsoC) was considered, although the D-monomers present in the published peptide sequences were deduced from predictive analysis and not yet experimentally confirmed (Dubern et al., 2008).

\section{Construction of pMQ30- $\triangle C L P 2$ and mutagenesis of CMR12a}

To construct mutants CMR12a- $\Delta$ CLP2 and CMR12a- $\Delta$ Phz$\triangle \mathrm{CLP} 2$, a large $(8 \mathrm{~kb})$ fragment of the CLP2 biosynthesis genes was deleted by allelic replacement with vector pMQ30 (Hoang et al., 1998; Shanks et al., 2006). Two coding regions, located approximately in the middle of ofaB and ofaC of CMR12a, were amplified with primers CLP2-Up-F and CLP2-Up-R (1003 bp) and primers CLP2-Down-F and CLP2Down-R (989 bp) respectively. These two polymerase chain reaction (PCR) products were cloned next to each other via in vivo homologous recombination in the yeast $S$. cerevisiae InvSc1, resulting in deletion plasmid pMQ30- $\triangle$ CLP2. This plasmid was mobilized into CMR12a and CMR12a- $\Delta \mathrm{Phz}$ by conjugation with E.coli BW29427 and selection on gentamycin. Next, transconjugants that had lost the plasmid during a second crossover event were selected on $10 \%$ sucrose, whereupon the deletion was confirmed by PCR. Finally, the two resulting mutants were subjected to another round of mutagenesis with pEX18Tc-CLP1, as described by D'aes and colleagues (2011), to obtain CMR12a- $\triangle$ CLP2CLP1 and CMR12a- $\triangle$ Phz- $\triangle$ CLP2-CLP1.

\section{Analysis of phenazine and CLP production by CMR12a biosynthesis mutants}

The presence of phenazines in a culture extract was determined by thin-layer chromatography and HPLC (Perneel et al., 2007). Spectrophotometric measurements on a cell-free culture supernatant $(\lambda=369 \mathrm{~nm}$ and $\varepsilon=$ $11393 \mathrm{M}^{-1} \mathrm{~cm}^{-1}$ ) provided quantitative data for phenazine production.

Production of CLPs was first tested qualitatively by the drop collapse technique (Jain et al., 1991). In addition, surface tension of a cell-free culture supernatant was measured with the Wilhelmy plate method, as described by Perneel and colleagues (2007) with minor modifications. For LC-ESI-MS analysis, supernatant samples were collected after $72 \mathrm{~h}$ of growth on KB medium and subjected to reverse phase LC-ESI-MS as described above.

\section{Swarming motility assays}

Swarming motility of CMR12a and its mutants was tested on MLB medium (contains $40 \%$ of the nutrients of LB) and SSM (De Bruijn et al., 2008) with $0.6 \%$ agar. Cultures were grown during $16 \mathrm{~h}$ in LB broth and washed twice with saline solution $(0.85 \%)$. Five microlitres of the suspensions was spotted in the centre of the plates and incubated at $28^{\circ} \mathrm{C}$ for $24 \mathrm{~h}$ (MLB medium) or $48 \mathrm{~h}$ (SSM). For complementation assays, the two bacterial suspensions were mixed in equal volumes, and $5 \mu \mathrm{l}$ of the mixture was spotted. At least three replicates per strain were included, and the experiments were repeated at least twice.

\section{Biofilm formation assays}

Development of biofilms in polystyrene 96-well plates was tested according to a method adapted from Maddula and colleagues (2006) and Merrit and colleagues (2005). Wells of a polystyrene 96 -well flat bottom microtiter plate were filled with $120 \mu \mathrm{l} A B$ minimal medium amended with $2 \%$ casamino acids (CAA) (Schleif and Wensink, 1981) and inoculated with $1.2 \mu \mathrm{l}$ of overnight bacterial cultures in LB broth, diluted to an $\mathrm{OD}_{620}$ of 0.8 . Per treatment, 11 replicates were included. Plates were incubated at $28^{\circ} \mathrm{C}$ for up to $72 \mathrm{~h}$, and development of a biofilm at the air-liquid interface was assessed at different time points. For each time point, $\mathrm{OD}_{620}$ of a plate was measured, after which unbound cells and medium were removed by thoroughly rinsing with tap water. To colour the attached cells, $150 \mu \mathrm{l}$ of $0.1 \%$ crystal violet solution in water was added to each well, following incubation for $10 \mathrm{~min}$ at room temperature. Unbound crystal violet was removed by immersing the plates twice in tap water, and $200 \mu$ of $95 \%$ ethanol was added to the wells to re-dissolve the cell-bound crystal violet. Subsequently, $120 \mu$ of the crystal violet solution in $95 \%$ ethanol was transferred to a new 96-well plate, and the optical density was measured at $595 \mathrm{~nm}$. Experiments were repeated at least twice. For statistical data analy- 
sis, non-parametric Kruskal-Wallis and Mann-Whitney $U$-tests $(\alpha=0.05)$ were performed.

\section{Analysis of sessilin and orfamide production under biofilm or swarming conditions}

All cells were scraped from the swarming plates and diluted in $6 \mathrm{ml} \mathrm{ACN} /$ water 50/50 v/v. The mixture was ultrasonicated for $2 \mathrm{~min}$, centrifuged at 14000 r.p.m. during $20 \mathrm{~min}$ and then $1 \mathrm{ml}$ was injected in LC-ESI-MS for analysis.

Production of CLPs under conditions of biofilm formation in 96-well plates was measured directly in the liquid material collected and pooled from 15 wells. The resulting sample was centrifuged at 14000 r.p.m. for $10 \mathrm{~min}$ and injected as such in LC-ESI-MS for analysis.

\section{White-line-in-agar assay}

The white-line-in-agar test was performed in triplicate on KB (Rokni-Zadeh et al., 2012). Cultures were grown during $16 \mathrm{~h}$ in LB broth and washed twice with saline solution $(0.85 \%)$. The line of bacterial strains in the middle of the plates was made from three drops $\left(5 \mu \mathrm{l}\right.$ drop $\left.^{-1}\right)$ of the suspension. After that, $5 \mu$ of each bacterial strain suspension was spotted at both sides of the line with $1 \mathrm{~cm}$ distance. White precipitate formation in the agar was evaluated after 6 days of growth at $28^{\circ} \mathrm{C}$.

\section{Acknowledgements}

The authors thank Harald Gross and Joyce Loper for kindly providing strain $P$. protegens Pf-5 and a purified orfamide sample. This work was supported by a specialization fellowship of the Flemish Institute for the Stimulation of ScientificTechnological Research in Industry (IWT, Belgium) to J. D'aes, by the INTERREG IV programme France-WallonieVlaanderen (Phytobio project) and by a grant from the Research Foundation Flanders (FWO project 3G.002.10N). $M$. Ongena is a research associate at the National Funds for Scientific Research in Belgium. The mass spectrometry facilities used for this study are funded by the European community (FEDER), the Région Nord-Pas de Calais (France), the IBISA (Infrastructures en Biologie Santé et Agronomie) network, the CNRS, the Université Lille 1 Sciences et Technologies and the TGE FT-ICR. The authors thank Geoffrey Vauvy for the preparation of desalted samples prior to MS analysis.

\section{References}

Andersen, J.B., Koch, B., Nielsen, T.H., Sorensen, D., Hansen, M., Nybroe, O., et al. (2003) Surface motility in Pseudomonas sp. DSS73 is required for efficient biological containment of the root-pathogenic microfungi Rhizoctonia solani and Pythium ultimum. Microbiology 149: 37-46.

Bachmann, B.O., and Ravel, J. (2009) In silico prediction of microbial secondary metabolic pathways from DNA sequence data. Methods Enzymol 458: 181-217.
Balibar, C.J., Vaillancourt, F.H., and Walsh, C.T. (2005) Generation of $D$ amino acid residues in assembly of arthrofactin by dual condensation/epimerization domains. Chem Biol 12: 1189-1200.

Barahona, E., Navazo, A., Yousef-Coronado, F., Aguirre de Carcer, D., Martinez-Granero, F., EspinozaUrgel, M., et al. (2010) Efficient rhizosphere colonization by Pseudomonas fluorescens $\mathrm{f113}$ mutants unable to form biofilms on abiotic surfaces. Environ Microbiol 12: 31853195.

Bassarello, C., Lazzaroni, S., Bifulco, G., Lo Cantore, P., lacobellis, N.S., Riccio, R., et al. (2004) Tolaasins A-E, five new lipodepsipeptides produced by Pseudomonas tolaasii. $J$ Nat Prod 67: 811-816.

Batoko, H., d'Exaerde, A.D., Kinet, J.M., Bouharmont, J., Gage, R.A., Maraite, H., and Boutry, M. (1998) Modulation of plant plasma membrane $\mathrm{H}+$-ATPase by phytotoxic lipodepsipeptides produced by the plant pathogen Pseudomonas fuscovaginae. Biochim Biophys ActaBiomembr 1372: 216-226.

Bender, C.L., Alarcon-Chaidez, F., and Gross, D.C. (1999) Pseudomonas syringae phytotoxins: mode of action, regulation, and biosynthesis by peptide and polyketide synthetases. Microbiol Mol Biol Rev 63: 266-292.

Brodey, C.L., Rainey, P.B., Tester, M., and Johnstone, K. (1991) Bacterial blotch disease of the cultivated mushroom is caused by an ion channel forming lipodepsipeptide toxin. Mol Plant Microbe Interact 4: 407-411.

de Bruijn, I., de Kock, M.J.D., Yang, M., de Waard, P., van Beek, T.A., and Raaijmakers, J.M. (2007) Genome-based discovery, structure prediction and functional analysis of cyclic lipopeptide antibiotics in Pseudomonas species. Mol Microbiol 63: 417-428.

Burlinson, P., Studholme, D., Cambray-Young, J., Heavens, D., Rathjen, J., Hodgkin, J., and Preston, G.M. (2013) Pseudomonas fluorescens NZI7 repels grazing by $C$. elegans, a natural predator. ISME J 7: 1126-1138.

Chevreux, B., Wetter, T., and Suhai, S. (1999) Genome sequence assembly using trace signals and additional sequence information. In Computer Science and Biology: Proceedings of the German Conference on Bioinformatics (GCB) 99, Hannover, Germany. pp. 45-56.

D'aes, J., De Maeyer, K., Pauwelyn, E., and Höfte, M. (2010) Biosurfactants in plant-Pseudomonas interactions and their importance to biocontrol. Environ Microbiol Rep 2: 359-372.

D’aes, J., Hua, G.K.H., De Maeyer, K., Pannecoucque, J., Forrez, I., Ongena, M., et al. (2011) Biological control of Rhizoctonia root rot on bean by phenazine and cyclic lipopeptide producing Pseudomonas CMR12a. Phytopathology 101: 996-1004.

Darling, A.C.E., Mau, B., Blattner, F.R., and Perna, N.T. (2004) Mauve: multiple alignment of conserved genomic sequence with rearrangements. Genome Res 14: 13941403.

De Bruijn, I., and Raaijmakers, J.M. (2009) Diversity and functional analysis of LuxR-type transcriptional regulators in cyclic lipopeptide biosynthesis in Pseudomonas fluorescens. Appl Environ Microbiol 75: 4753-4761.

De Bruijn, I., de Kock, M.J.D., de Waard, P., van Beek, T.A., and Raaijmakers, J.M. (2008) Massetolide A 
biosynthesis in Pseudomonas fluorescens. J Bacteriol 190: 2777-2789.

De Maeyer, K., D'aes, J., Hua, G.K.H., Perneel, M., Vanhaecke, L., Noppe, H., and Höfte, M. (2011) $\mathrm{N}$-Acylhomoserine lactone quorum-sensing signalling in antagonistic phenazine-producing Pseudomonas isolates from the red cocoyam rhizosphere. Microbiology 157: 459472.

De Maeyer, K., D'aes, J., Hua, G.K.H., Kieu, N.P., and Höfte, M. (2013) N-acetylhomoserine lactone quorum sensing signaling in phenazine and cyclic lipopeptide producing Pseudomonas sp. CMR12a from the red cocoyam rhizosphere. In Molecular Microbial Ecology of the Rhizosphere. de Bruijn, F.J. (ed.). Hoboken, NJ, USA: John Wiley and Sons, pp. 763-774.

Delcher, A.L., Bratke, K.A., Powers, E.C., and Salzberg, S.L. (2007) Identifying bacterial genes and endosymbiont DNA with Glimmer. Bioinformatics 23: 673-679.

Dubern, J.F., Coppoolse, E.R., Stiekema, W.J., and Bloemberg, G.V. (2008) Genetic and functional characterization of the gene cluster directing the biosynthesis of putisolvin I and II in Pseudomonas putida strain PCL1445. Microbiology 154: 2070-2083.

Dutta, S., and Podile, A.R. (2010) Plant growth promoting rhizobacteria (PGPR): the bugs to debug the root zone. Crit Rev Microbiol 36: 232-244.

Feil, H., Feil, W.S., Chain, P., Larimer, F., DiBartolo, G., Copeland, A., et al. (2005) Comparison of the complete genome sequences of Pseudomonas syringae pv. syringae B728a and pv. tomato DC3000. Proc Natl Acad Sci USA 102: 11064-11069.

Finking, R., and Marahiel, M.A. (2004) Biosynthesis of nonribosomal peptides. Annu Rev Microbiol 58: 453-488.

Gross, H., and Loper, J.E. (2009) Genomics of secondary metabolite production by Pseudomonas spp. Nat Prod Rep 26: 1408-1446.

Gross, H., Stockwell, V.O., Henkels, M.D., Nowak-Thompson, B., Loper, J.E., and Gerwick, W.H. (2007) The genomisotopic approach: a systematic method to isolate products of orphan biosynthetic gene clusters. Chem Biol 14: 53-63.

Hoang, T.T., Karkhoff-Schweizer, R.R., Kutchma, A.J., and Schweizer, H.P. (1998) A broad-host-range Flp-FRT recombination system for site-specific excision of chromosomally-located DNA sequences: application for isolation of unmarked Pseudomonas aeruginosa mutants. Gene 212: 77-86.

Hutchison, M.L., and Johnstone, K. (1993) Evidence for the involvement of the surface active properties of the extracellular toxin tolaasin in the manifestation of brown blotch disease symptoms by Pseudomonas tolaasii on Agaricus bisporus. Physiol Mol Plant Pathol 42: 373384.

lacobellis, N.S., Lavermicocca, P., Grgurina, I., Simmaco, M., and Ballio, A. (1992) Phytotoxic properties of Pseudomonas syringae pv. syringae toxins. Physiol Mol Plant Pathol 40: 107-116.

Jain, D.K., Collinsthompson, D.L., Lee, H., and Trevors, J.T. (1991) A drop-collapsing test for screening surfactantproducing microorganisms. J Microbiol Methods 13: 271279.
Jourdan, E., Henry, G., Duby, F., Dommes, J., Barthelemy, J.P., Thonart, P., and Ongena, M. (2009) Insights into the defense-related events occurring in plant cells following perception of surfactin-type lipopeptide from Bacillus subtilis. Mol Plant Microbe Interact 22: 456-468.

Juhas, M., van der Meer, J.R., Gaillard, M., Harding, R.M., Hood, D.W., and Crook, D.W. (2009) Genomic islands: tools of bacterial horizontal gene transfer and evolution. FEMS Microbiol Rev 33: 376-393.

King, E.O., Ward, M.K., and Raney, D.E. (1954) Two simple media for the demonstration of pyocyanin and fluorescein. $J$ Lab Clin Med 44: 301-307.

Kuiper, I., Lagendijk, E.L., Pickford, R., Derrick, J.P., Lamers, G.E.M., Thomas-Oates, J.E., et al. (2004) Characterization of two Pseudomonas putida lipopeptide biosurfactants, putisolvin I and II, which inhibit biofilm formation and break down existing biofilms. Mol Microbiol 51: 97-113.

Kunkel, B.N., and Zhongying, C. (2006) Virulence of plant pathogenic bacteria. In Prokaryotes. Dworkin, M., Falkow, F., Rosenberg, E., Schleifer, K.H., and Stackebrandt, E. (eds). New York, NY, USA: Springer, pp. 421-440.

Li, W., Rokni-Zadeh, H., De Vleeschouwer, M., Ghequire, M.G.K., Sinnaeve, D., Xie, G.L., et al. (2013) The antimicrobial compound xantholysin defines a new group of Pseudomonas cyclic lipopeptides. PLOS ONE 8: e62946.

López, D., Fischbach, M.A., Chu, F., Losick, R., and Kolter, R. (2009) Structurally diverse natural products that cause potassium leakage trigger multicellularity in Bacillus subtilis. Proc Natl Acad Sci USA 106: 280-285.

Lo Cantore, P., Lazzaroni, S., Coraiola, M., Dalla Serra, M., Cafarchia, C., Evidente, A., and lacobellis, N.S. (2006) Biological characterization of white line-inducing principle (WLIP) produced by Pseudomonas reactans NCPPB1311. Mol Plant Microbe Interact 19: 1113-1120.

Maddula, V., Zhang, Z., Pierson, E.A., and Pierson, L.S. (2006) Quorum sensing and phenazines are involved in biofilm formation by Pseudomonas chlororaphis (aureofaciens) strain 30-84. Microb Ecol 52: 289-301.

Maddula, V.S., Pierson, E.A., and Pierson, L.S., 3rd (2008) Altering the ratio of phenazines in Pseudomonas chlororaphis (aureofaciens) strain 30-84: effects on biofilm formation and pathogen inhibition. J Bacteriol 190: 27592766.

Mavrodi, D.V., Blankenfeldt, W., and Thomashow, L.S. (2006) Phenazine compounds in fluorescent Pseudomonas spp. biosynthesis and regulation. Annu Rev Phytopathol 44: 417-445.

Mavrodi, D.V., Peever, T.L., Mavrodi, O.V., Parejko, J.A., Raaijmakers, J.M., Lemanceau, P., et al. (2010) Diversity and evolution of the phenazine biosynthesis pathway. Appl Environ Microbiol 76: 866-879.

Mazzola, M., de Bruijn, I., Cohen, M.F., and Raaijmakers, J.M. (2009) Protozoan-induced regulation of cyclic lipopeptide biosynthesis is an effective predation defense mechanism for Pseudomonas fluorescens. Appl Environ Microbiol 75: 6804-6811.

Merrit, J.H., Kadouri, D.E., and O'Toole, G.A. (2005) Growing and analyzing static biofilms. In Current Protocols in Microbiology. Coico, R., Kowalik, T., Quarles, J., Stevenson, B., 
and Taylor, R. (eds). Hoboken, NJ, USA: J. Wiley \& Sons, pp. 1B.1.1-1B.1.17.

Morikawa, M., Hirata, Y., and Imanaka, T. (2000) A study on the structure-function relationship of lipopeptide biosurfactants. Biochim Biophys Acta-Mol Cell Biol Lipids 1488: 211-218.

Mortishire-Smith, R.J., Nutkins, J.C., Packman, L.C., Brodey, C.L., Rainey, P.B., Johnstone, K., and Williams, D.H. (1991) Determination of the structure of an extracellular peptide produced by the mushroom saprotroph Pseudomonas reactans. Tetrahedron 47: 3645-3654.

Nutkins, J.C., Mortishire-Smith, R.J., Packman, L.C., Brodey, C.L., Rainey, P.B., Johnstone, K., and Williams, D.H. (1991) Structure determination of tolaasin, an extracellular lipodepsipeptide produced by the mushroom pathogen Pseudomonas tolaasii paine. J Am Chem Soc 113: 26212627.

Paulsen, I.T., Press, C.M., Ravel, J., Kobayashi, D.Y., Myers, G.S.A., Mavrodi, D.V., et al. (2006) Complete genome sequence of the plant commensal Pseudomonas fluorescens Pf-5. Nat Biotechnol 24: 466-466.

Pauwelyn, E., Huang, C.-J., Ongena, M., Leclère, V., Jacques, P., Bleyaert, P., et al. (2013) New linear lipopeptides produced by Pseudomonas cichorii SF1-54 are involved in virulence, swarming motility, and biofilm formation. Mol Plant Microbe Interact 26: 585-598.

Perneel, M., Heyrman, J., Adiobo, A., De Maeyer, K., Raaijmakers, J.M., De Vos, P., and Hofte, M. (2007) Characterization of CMR5c and CMR12a, novel fluorescent Pseudomonas strains from the cocoyam rhizosphere with biocontrol activity. J Appl Microbiol 103: 10071020.

Raaijmakers, J.M., de Bruijn, I., and de Kock, M.J.D. (2006) Cyclic lipopeptide production by plant-associated Pseudomonas spp.: diversity, activity, biosynthesis, and regulation. Mol Plant Microbe Interact 19: 699-710.

Raaijmakers, J.M., de Bruijn, I., Nybroe, O., and Ongena, M. (2010) Natural functions of lipopeptides from Bacillus and Pseudomonas: more than surfactants and antibiotics. FEMS Microbiol Rev 34: 1037-1062.

Ramos, I., Dietrich, L.E.P., Price-Whelan, A., and Newman, D.K. (2010) Phenazines affect biofilm formation by Pseudomonas aeruginosa in similar ways at various scales. Res Microbiol 161: 187-191.

Rausch, C., Weber, T., Kohlbacher, O., Wohlleben, W., and Huson, D.H. (2005) Specificity prediction of adenylation domains in nonribosomal peptide synthetases (NRPS) using transductive support vector machines (TSVMs). Nucleic Acids Res 33: 5799-5808.

Rausch, C., Hoof, I., Weber, T., Wohlleben, W., and Huson, D.H. (2007) Phylogenetic analysis of condensation domains in NRPS sheds light on their functional evolution. BMC Evol Biol 7: 78.

Rokni-Zadeh, H., Li, W., Sanchez-Rodriguez, A., Sinnaeve, D., Rozenski, J., Martins, J.C., and De Mot, R. (2012) Genetic and functional characterization of cyclic lipopeptide white-line-inducing principle (WLIP) production by rice rhizosphere isolate Pseudomonas putida RW10S2. Appl Environ Microbiol 78: 4826-4834.

Rokni-Zadeh, H., Li, W., Yilma, E., Sanchez-Rodriguez, A., and De Mot, R. (2013) Distinct lipopeptide production systems for WLIP (white line-inducing principle) in Pseudomonas fluorescens and Pseudomonas putida. Environ Microbiol Rep 5: 160-169.

Roongsawang, N., Hase, K., Haruki, M., Imanaka, T., Morikawa, M., and Kanaya, S. (2003) Cloning and characterization of the gene cluster encoding arthrofactin synthetase from Pseudomonas sp MIS38. Chem Biol 10: 869-880.

Roongsawang, N., Lim, S.P., Washio, K., Takano, K., Kanaya, S., and Morikawa, M. (2005) Phylogenetic analysis of condensation domains in the nonribosomal peptide synthetases. FEMS Microbiol Lett 252: 143-151.

Sambrook, J., Fritsch, E.F., and Maniatis, T. (1989) Molecular Cloning: A Laboratory Manual. New York, NY, USA: Cold Spring Harbor Laboratory Press, Cold Spring Harbor.

Schleif, R.F., and Wensink, P.C. (1981) Practical Methods in Molecular Biology. New York, NY, USA: Springer-Verlag.

Scholz-Schroeder, B.K., Hutchison, M.L., Grgurina, I., and Gross, D.C. (2001) The contribution of syringopeptin and syringomycin to virulence of Pseudomonas syringae pv. syringae strain B301D on the basis of sypA and syrB1 biosynthesis mutant analysis. Mol Plant Microbe Interact 14: 336-348.

Scholz-Schroeder, B.K., Soule, J.D., and Gross, D.C. (2003) The $\operatorname{syp} A, \operatorname{syp} B$ and $\operatorname{syp} C$ synthetase genes encode twenty-two modules involved in the nonribosomal peptide synthesis of syringopeptin by Pseudomonas syringae pv. syringae B301D. Mol Plant Microbe Interact 16: 271280.

Selin, C., Habibian, R., Poritsanos, N., Athukorala, S.N.P., Fernando, D., and de Kievit, T.R. (2010) Phenazines are not essential for Pseudomonas chlororaphis PA23 biocontrol of Sclerotinia sclerotiorum, but do play a role in biofilm formation. FEMS Microbiol Ecol 71: 73-83.

Shanks, R.M.Q., Caiazza, N.C., Hinsa, S.M., Toutain, C.M., and O'Toole, G.A. (2006) Saccharomyces cerevisiaebased molecular tool kit for manipulation of genes from gram-negative bacteria. Appl Environ Microbiol 72: 50275036.

Singh, G.M., Vaillancourt, F.H., Yin, J., and Walsh, C.T. (2007) Characterization of SyrC, an aminoacyltransferase shuttling threonyl and chlorothreonyl residues in the syringomycin biosynthetic assembly line. Chem Biol 14: 31-40.

Vallet-Gely, I., Novikov, A., Augusto, L., Liehl, P., Bolbach, G., Pechy-Tarr, M., et al. (2010) Association of hemolytic activity of Pseudomonas entomophila, a versatile soil bacterium, with cyclic lipopeptide production. Appl Environ Microbiol 76: 910-921.

Verstraeten, N., Braeken, K., Debkumari, B., Fauvart, M., Fransaer, J., Vermant, J., and Michiels, J. (2008) Living on a surface: swarming and biofilm formation. Trends Microbiol 16: 496-506.

Wong, W.C., and Preece, T.F. (1979) Identification of Pseudomonas tolaasi - white line in agar and mushroom tissue block rapid pitting tests. J Appl Bacteriol 47: 401407.

Zerbino, D.R., and Birney, E. (2008) Velvet: algorithms for de novo short read assembly using de Bruijn graphs. Genome Res 18: 821-829. 


\section{Supporting information}

Additional Supporting Information may be found in the online version of this article at the publisher's web-site:

Fig. S1. Chromatogram of HPLC analysis of acid hydrolysate of sessilin A. Amino acid peaks were assigned based on amino acid standards, and relative amounts of each amino acid present in the hydrolysate were calculated based on standard curves obtained for each amino acid standard. Glx, glutamine or glutamate; Ser, serine; Hse, homoserine; dhAbu, 2,3-dehydro-2-aminobutyric acid; aThr, allothreonine; Val, valine; Ile, isoleucine; Leu, leucine; Lys, lysine; Dab, 2,4-diaminobutyric acid; Pro, proline.

Fig. S2. Chromatogram of HPLC analysis of acid hydrolysate of orfamide E. Amino acid peaks were assigned based on amino acid standards, and relative amounts of each amino acid present in the hydrolysate were calculated based on standard curves obtained for each amino acid standard. Glx, glutamine or glutamate; Ser, serine; aThr, allothreonine; Val, valine; Leu, leucine.

Fig. S3. High-resolution spectra of sessilin A. (A) NanoESIQh-FT-ICR MS spectrum showing the isotopic pattern of the doubly charged sessilin $\mathrm{A} \mathrm{C}_{96} \mathrm{H}_{168} \mathrm{O}_{25} \mathrm{~N}_{22}(\Delta \mathrm{m}=1.08$ p.p.m. on monoisotopic peak, $\Delta \mathrm{m}=0.01$ p.p.m. on more abundant isotopic peak); the peaks annotated with asterisk are issued from a second doubly charged pattern corresponding to $\mathrm{C}_{96} \mathrm{H}_{166} \mathrm{O}_{25} \mathrm{~N}_{22}, \quad(\Delta \mathrm{m}=0.88$ p.p.m. on monoisotopic peak, $\Delta \mathrm{m}=0.98$ p.p.m. on more abundant isotopic peak). (B) Theoretical spectrum of the doubly charged species $\mathrm{C}_{96} \mathrm{H}_{168} \mathrm{O}_{25} \mathrm{~N}_{22}$ C. Theoretical spectrum of the doubly charged species $\mathrm{C}_{96} \mathrm{H}_{166} \mathrm{O}_{25} \mathrm{~N}_{22}$.

Fig. S4. NanoESI-Qh-FT-ICR ECD spectrum of sessilin A $\left(\mathrm{C}_{96} \mathrm{H}_{168} \mathrm{O}_{25} \mathrm{~N}_{22}\right)$. Details related to ion molecular formulae and $\Delta \mathrm{m}$ are presented in Supporting Information Table S1. dhAbu, 2,3-dehydro-2-aminobutyric acid; Pro, proline; Ser, serine; Leu, leucine; Val, valine; GIn, glutamine; Leu, leucine; Thr, threonine; Ile, isoleucine; Hse, homoserine; Dab, 2,4diaminobutyric acid; Lys, lysine.

Fig. S5. NanoESI-Qh-FT-ICR ECD spectrum of orfamide $E$ $\left(\mathrm{C}_{63} \mathrm{H}_{112} \mathrm{O}_{17} \mathrm{~N}_{10}\right)$. Details related to ion molecular formulae and $\Delta \mathrm{m}$ are presented in Supporting Information Table S2. Leu, leucine; Glu, glutamate; Thr, threonine; Val, valine; Ser, serine.

Fig. S6. Phylogenetic tree constructed for condensation domains extracted from synthetases for syringopeptin (SypA, SypB and SypC) and syringomycin (SyrE) from $P$. syringae pv. syringae B301D, arthrofactin (ArfA, ArfB and ArfC) from Pseudomonas sp. MIS38, putisolvin (PsoA, PsoB and PsoC) from P. putida PCL1445, massetolide (MassA, MassB and MassC) from $P$. fluorescens SS101, orfamide (OfaA, OfaB and OfaC) from P. fluorescens Pf-5 and sessilin (SesA, SesB and SesC) and orfamide (designated as OfaA-12a, OfaB-12a and OfaC-12a to avoid confusion with OfaA, OfaB and OfaC from $P$. fluorescens Pf-5). Black and white arrows indicate sessilin $C$ domains and orfamide $C$ domains respectively. C domain, condensation domain; dual C/E domain, dual condensation/epimerization domain.

Fig. S7. ESI-MS spectra presenting analysis of sessilin and orfamide production by Pseudomonas CMR12a and the new sessilin (Clp1) and orfamide (Clp2) mutants that were con- structed in this study. $y$-Axis represents relative intensity. $\Delta \mathrm{Phz}$, mutation in phenazine biosynthesis.

Fig. S8. Swarming ability of CMR12a and CLP mutants on soft MLB medium or soft MLB medium supplied with a semipurified orfamide extract. Semi-purified orfamide extract was obtained from a culture of Pseudomonas CMR5c (a biocontrol strain that only produces orfamide, not sessilin, and readily releases orfamide in the medium) in KB medium by acidifying the supernatant with ethyl acetate, centrifugation and further extraction with methanol. After evaporation, the semi-purified orfamide extract was redissolved in ethanol. Orfamide was supplied at a final concentration of $4 \mu \mathrm{g} \mathrm{ml}^{-1}$ medium. Control plates were supplied with ethanol only. Bacterial cultures were grown during $16 \mathrm{~h}$ in LB broth and washed twice with saline solution $(0.85 \%)$. Five microlitres of the suspensions was spotted in the centre, and plates were incubated at $28^{\circ} \mathrm{C}$ for $24 \mathrm{~h}$ or $48 \mathrm{~h}$. CMR12a, wildtype Pseudomonas CMR12a; CMR12a-Clp1, sessilin biosynthesis mutant; CMR12a- $\Delta \mathrm{Clp} 2$, orfamide biosynthesis mutant; CMR12a- $\Delta$ Clp2-Clp1, orfamide and sessilin double mutant.

Fig. S9. Swarming ability of CMR12a and CLP mutants on soft MLB medium or soft MLB medium supplied with supernatant from orfamide or sessilin-producing strains. To produce supernatants, CMR12a-Clp1 (produces orfamide), CMR12a- $\Delta$ Clp2 (produces sessilin) and CMR12a- $\Delta$ Clp2Clp1 (negative control) were grown overnight in $50 \mathrm{ml} \mathrm{LB}$ at $28^{\circ} \mathrm{C}$. The supernatant was centrifuged to remove cells and filter sterilized. MLB medium was supplemented with $30 \%$ supernatant from each strain. Control media were supplied with $0 \%, 20 \%$ and $30 \%$ LB medium. A control with $20 \%$ LB medium was included because the bacteria will have used part of the nutrients in the LB medium. The final agar concentration was always $0.6 \%$. For inoculation, CMR12a and CLP mutants were grown during $16 \mathrm{~h}$ in LB broth and washed twice with saline solution $(0.85 \%)$. Five microlitres of the suspensions was spotted in the centre, and plates were incubated at $28^{\circ} \mathrm{C}$ for $24 \mathrm{~h}$ and $48 \mathrm{~h}$. The orfamidecontaining supernatant complements swarming in the orfamide-negative mutants; the sessilin-containing supernatant hampers swarming in the wild-type strain CMR12a, but not in the sessilin-negative Clp1 mutant. CMR12a, wild-type Pseudomonas CMR12a; CMR12a-Clp1, sessilin biosynthesis mutant; CMR12a- $\Delta$ Clp2, orfamide biosynthesis mutant; CMR12a- $\Delta$ Clp2-Clp1, orfamide and sessilin double mutant.

Fig. S10. Analysis of white line by MALDI-ToF mass spectrometry. Left: schematic representation of white line formation during the interaction among the CMR12a- $\Delta$ Clp2 mutant (middle), the CMR12a-Clp1 mutant (bottom) and CMR12a$\Delta$ Clp2-Clp1 mutant (top). Red circles represent the locations of medium sampling close to CMR12a- $\Delta$ Clp2, close to CMR12a-Clp1 and in the white line. Right: typical molecular ions $\left(\mathrm{m} / \mathrm{z}\right.$ for $[\mathrm{M}+\mathrm{H}]^{+}$or $[\mathrm{M}+\mathrm{Na}]^{+*}$, n.d., not detected) corresponding to the three sessilins (S-A, S-B and S-C) and orfamides (Ofa-D, Ofa-E and Ofa-B) detected by MALDI-ToF in the plugs sampled from the KB agar medium at the locations indicated.

Table S1. Mass measurement errors on molecular and fragment ions resulting from sessilin A nanoESI-Qh-FT-ICR MS ECD experiments (Fig. 3). 
Table S2. Mass measurement errors on molecular and fragment ions resulting from orfamide $E$ nanoESI-Qh-FT-ICR MS ECD experiments (Fig. 4).

Table S3. Strains, plasmids and primers used in this study. Primer extensions are in italic font. "PHZ, phenazines; CLP, cyclic lipopeptide; CLP1, sessilin; CLP2, orfamide; GmR, TcR, AmpR, KmR, resistant to gentamycin, tetracyclin, ampicillin, kanamycin respectively; BCCM, Belgian Co-ordinated Collections of Microorganisms. 